\title{
A Mutualism, Affiliation and Status Seeking (MASS) Framework of Fundamental Affective Dynamics and their Survival Benefits
}

Dean Mobbs ${ }^{1 *}$, Sarah M. Tashjian ${ }^{1}$, and Brian Silston ${ }^{2}$

${ }^{1}$ Humanities and Social Sciences, California Institute of Technology (Caltech), Pasadena, CA, USA

${ }^{2}$ Department of Psychology, Columbia University, New York, NY, USA

${ }^{*}$ Correspondence author:

Dean Mobbs PhD

Humanities and Social Sciences

319 Baxter Hall

California Institute of Technology (Caltech), Pasadena, California, 91125

MC 228-77

Phone: +1 6267148913

Email:dmobbs@caltech.edu 


\section{Social and Affective Dynamics and their Survival Benefits}

Abstract Primates have developed a unique set of complex drives for successful group living, yet theorists rarely contemplate their taxonomy and how such drives relate to affective dynamics fundamental for group success. Affective dynamics and drive fulfillment exert mutual influence on one another, ultimately collectively promoting or undermining survival. We first identify six core benefits of group living common among both humans and other animals, and from this foundation we propose three broad social drives that have evolved to preserve or enhance group living benefits: (i) Mutualism comprises cooperation, reciprocity, trust, and fairness; (ii) Affiliation comprises assimilation and belonging, whereby one aims to fit into the group through adherence to group norms and ideologies; (iii) Status-Seeking is represented by a drive to build one's value in the group and acquire differential access to mates and other resources. We identify affective dynamics that facilitate each social drive: (i) Reactive flexibility involves qualitative shifts in affect in response to shifting goals, which facilitates mutualism; (ii) Affective synchrony is the reproduction of another individual's emotions in oneself and facilitates social affiliation; (iii) Regulatory flexibility facilitates status-seeking through a broad repertoire of regulatory approaches during strategic behavioral pursuits. Finally, we posit that fulfilling Mutualism, Affiliation, and Status-Seeking (MASS) drives enhances the benefits of social living and supports development of fundamental affective dynamics. 


\section{Social and Affective Dynamics and their Survival Benefits}

A preparedness for sociality is ubiquitous across organisms. At its most basic level, social behavior is observed in microbes and invertebrates (Anstey, Rogers, Ott, Burrows, \& Simpson, 2009; Carlisle \& Ellis, 1963; Henke \& Bassler, 2004), yet becomes increasingly complex in rodents and non-human primates. Sociality is preeminent in humans and occurs early in development. Fetal twins, for example, show social interaction in the womb (Castiello et al., 2010), newborns show an instant preference for the human face (Valenza, Simion, Cassia, \& Umilta, 1996), infants quickly understand that others have inner minds (Onishi \& Baillargeon, 2005) and exhibit complex social rules including egalitarianism and aversion to inequity (Fehr, Bernhard, \& Rockenbach, 2008; Svetlova, Nichols, \& Brownell, 2010; Tomasello, Carpenter, Call, Behne, \& Moll, 2005). While most other species have evolved to survive by winning power struggles and attraction contests over competitors, humans have evolved a prodigious social intelligence unmatched by other species. Social living necessarily involves affective dynamics - emotions are inherently social. Social others elicit emotions, emotions facilitate communication between individuals and groups, and emotion regulation influences behavior of others and social approval (van Kleef et al. 2016). Emotions that emphasize survival through development of social bonds and in response to social problems allow humans to transcend individual weaknesses and achieve unparalleled collective progress.

It has long been thought that survival needs drive the motivation system which in turn drives a set of rules for behavior (Maslow, 1943; Tolman, 1932). Here, we first establish the adaptive function of sociality by delineating a set of survival benefits conferred by the evolution of social groups, extending from the micro (i.e. individual) to the macro benefits of group living. Second, we propose three core social drives serving as the engines that motivate the successful acquisition of group living benefits. These drives include: Mutualism, Affiliation, and StatusSeeking (MASS drives). Third, we identify affective dynamics critical to and influenced by each social drive. Identifying and discerning the socio-affective features that facilitate the acquisition of group living benefits is a starting point from which to understand the evolution and organization of the human social brain.

\section{Six benefits of group living}

Paleontologists have shown that the primate species have been living in groups for approximately 52 million years (Shultz, Opie, \& Atkinson, 2011). While the disadvantages to group living are apparent (e.g. competition, resource depletion and spread of disease), clear benefits do exist. We propose that the benefits of social living can be categorized into six core themes. Several of these benefits are universal, observed across multiple group living species and are basic social ingredients in promoting the survival of the species. These include antipredation, increased mating opportunities, group aggression, social foraging, and decreased infant mortality (Alexander, 1974; Terborgh \& Janson, 1986). In many other social animals, the benefits are much richer and extend to higher-order benefits including social learning, information sharing, social support and collective intelligence. Group benefits also include the ultimate evolutionary benefit of passing on one's genes, thereby defining sociality as an 


\section{Social and Affective Dynamics and their Survival Benefits}

extremely useful engine to enhance the fitness of the individual, its kin and the species (Fig. 1). These six benefits include:

\section{Reproduction and Offspring Survival}

Mating Opportunities. The adaptive advantages of being in a larger group are more variety and greater access to mates, obvious benefits for both sexes.

Genetic Diversity. Shuffling of different genetic material leads to greater diversity, and can be described by Mixability Theory, which proposes that the breakdown of gene combinations results in maximization of fitness by finding the best combination of genes (Livnat, Papadimitriou, Dushoff, \& Feldman, 2008); also see "Social Heterosis Theory" (Nonacs \& Kapheim, 2007)).

Alloparenting. Cooperative breeding has traditionally been linked to kin-selection theory, in which animals exclusively help genetically related individuals. However, converging evidence shows that some species assist in the rearing of non-kin (Clutton-Brock, 2002).

\section{Anti-predation and Protection}

Risk dilution and joint vigilance. The theory of risk dilution (i.e. safety in numbers) suggests that the larger the group of prey the smaller the chance a particular individual will fall victim to lethal attack by predators (Foster \& Treherne, 1981). Social animals also frequently develop a system to alert others of danger.

Group aggression. Group aggression is in effective way to acquire resources, increase protection, and reduce threat from enemies.

Stress reduction. Stress reduces with predation risk and increased availability of resources. Predation protection allows for free time to play, develop pedagogy, and engage in social learning.

\section{Sustenance}

Social foraging. Solitary foraging results in a clear disadvantage, placing the animal at increased risk of predation, starvation and reduced breadth of diet (Giraldeau, 1984; Krebs, 1972). Social foraging provides benefits to both the individual and the group, where others may have information about patches rich in food and patches with low risk of predation.

Food and resource sharing. Sharing of food and resources benefits individuals in times of need (e.g. food scarcity). Sharing is observed in hunter-gather populations (Gurven, 2004) and recent 


\section{Social and Affective Dynamics and their Survival Benefits}

research shows that Chimpanzees will share food with non-kin (Pruetz \& Lindshield, 2012) under certain circumstances.

\section{Social Learning and Information Sharing}

Vicarious learning. Social learning is defined as the organism's ability to receive, retain, learn from others, and the ability to reproduce the observed behavior (Bandura, 1962). Social learning is also apparent in other animals, and especially useful in unpredictable environments.

Information Sharing. Social psychological research has shown the benefits of taking advice from others. For example, surrogate advice by others provides more accurate information than selfpredictions in for novel event (Gilbert, Killingsworth, Eyre, \& Wilson, 2009). These studies support the idea that information sharing is critical to how we interact with others and provides rich information that can enhance socially adaptive behaviors.

\section{Wellbeing and Belonging}

Wellbeing. Extensive research shows that quality of life increases with high quality social bonds and support. Comparative studies demonstrate how living in groups can promote physiological health (Seeman \& McEwen, 1996) and reproductive success is significantly increased by the quality of relationships (Silk, 2007). In humans, poor social bonds can lead to poor health, social adjustment, and quality of life (Baumeister and Leary 1995a). Indeed, recent studies have shown that social isolation and loneliness correlate with increased mortality (Steptoe, Shankar, Demakakos, \& Wardle, 2013), cardiovascular disease, higher blood pressure, heightened inflammatory responses to stress, and infection (Barth, Schneider, \& von Kanel, 2010; Cohen, Doyle, Skoner, Rabin, \& Gwaltney, 1997; Eisenberger \& Cole, 2012; Loucks et al., 2006).

Belonging. The need to belong is a fundamental human drive that leads to the formation of resilient relational bonds (Baumeister and Leary 1995b). Belonging not only improves motivation, affect, and physical health, but connection to social others influences emotional experiences. For example, emotional and behavioral patterns flexibly adapt to group composition (Cottrell and Neuberg 2005).

\section{Collective Intelligence}

Group Wisdom and Skill Sharing. Group wisdom was creatively demonstrated by Galton's simple, yet ingenious, "ox" guesstimation study, which showed that when a crowd were asked to guess the weight of an ox, the average group response was within one pound of its actual weight (Galton, 1907). More recently, Wegner and colleagues showed that when people are paired in couples, those in a relationship perform better on a joint memory task than two strangers, (Wegner, Erber, \& Raymond, 1991) and Surowiecki (Surowiecki, 2004) showed that this group intelligence extends to such domains as stock markets and quiz shows. The ability and 


\section{Social and Affective Dynamics and their Survival Benefits}

capacity to frequently select optimal choices for the group derives from variance afforded by numbers and comparative abilities.

Division of labor. Complex biological systems are characterized by self-organizing processes that include specialized and domain general subcomponents that confer efficiencies and advantages to the organism. These organizational processes include a division of labor observed in eusocial insect species and higher animals including birds and primates (Arnold, Owens, \& Goldizen, 2005; Torres, Montagna, Raizer, \& Antonialli-Junior, 2012).
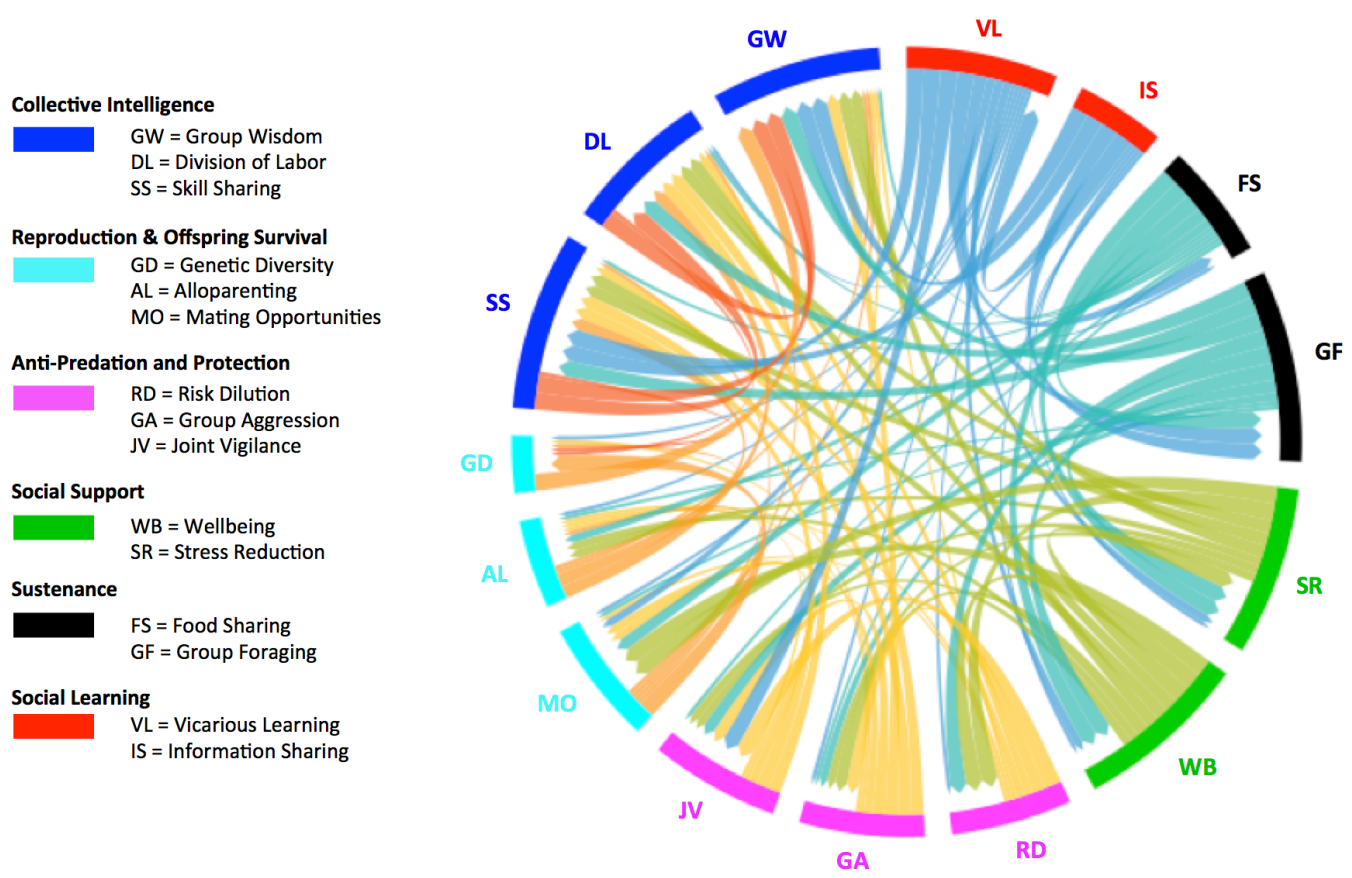

Fig. 1. The six benefits of group living and their interactions. Groupings are delineating by color - for example Collective Intelligence is represented by blue, and features Group Wisdom, Division of Labor and Skill Sharing. Thickness of the lines connecting different areas indicated the assumed strength of the interaction.

\section{Why a new theory of social motives?}

To realize the benefits of sociality described herein, a set of social drives must exist at the level of the individual to motivate successful integration and function within a social group. Several critical questions in psychology and neuroscience regarding the social nature of humans must be addressed to advance our understanding of human social motivation. These include: what motivates social behavior; why are some individuals good at social interaction while others are inept; and more generally, why are we social creatures? To probe these fundamental questions, we must consider the range and frequencies of human behaviors in social settings. Existing theories of social motivation have all contributed to understand these questions, however, meaningful differences between theories support the need for integration. Further, no obvious 


\section{Social and Affective Dynamics and their Survival Benefits}

explanatory framework arises as to the requirements for the success of social groups, or the particular needs that evolved to contribute to success that provide reciprocal benefits to the individual and group. While Fiske's drives (Belonging, Understanding, Controlling, Enhancing Self and Trusting; BUCET; Fiske, 2002) are loosely linked to survival value of self, kin, and group , other theories have not made connections to group survival (e.g., Self-Determination Theory; Deci \& Ryan, 2008) The ability of an individual to acquire the benefits outlined above depends on its success as a group living animal. In the next section, we argue that the benefits of social living can be mapped on to several core social drives.

\section{Three core social drives: Mutualism, Affiliation and Status-Seeking (MASS)}

We propose previous theories of social motivation can be consolidated into three core drives that coordinate the formation of individuals into social groups and thereby facilitate affective development and yield survival benefits. We use the broader term of 'Mutualism' to capture compliance and trusting drives (Deci \& Ryan, 2008; Fiske, 2002). Relatedness, belonging, and understanding all point to a drive to form social ties (Deci \& Ryan, 2008; McClelland, 1965). We adopt the term 'Affiliation' to encompass these drives. Existing theories also proposes a drive for power or control (Fiske, 2002; McClelland, 1965). We consolidate these into 'Status Seeking'. In contrast to previous theories, the MASS model encompasses individual and group interactions. The social dimension of group interactions necessitates addressing affective dynamics. Emotional feedback drives motivation in individuals within a group context to calibrate individual needs to optimize the dynamics for group success. Under this interactional feedback framework, we can explain why those of higher perceived status have greater influence, why we affiliate, why we act in mutually beneficial ways and how these together continually refine both individual and group level affective characteristics that result in social success. We point to reactive flexibility, affective synchrony, and regulatory flexibility as necessary for full realization of group-oriented survival benefits. Linking motivational drives to affective competencies accounts for substantial overlap between social and affective processes in the human brain. From this, we detail the three core social drives:

i. Mutualism: the drive toward mutually beneficial behaviors, such as reciprocal altruism, cooperation and collaboration. While upfront and sharing costs are incurred at the individual level, these factors benefit both the group and individual as a result of establishing trust and ability to accomplish more than any individual can alone. Social signals of benevolence increase the likelihood of accruing social support from other group members. Since most groups are small enough such that all individuals are acquainted, reputation can be generated and tracked by others, forming a basis for consistency and reliability among members. 


\section{Social and Affective Dynamics and their Survival Benefits}

ii. Affiliation: the drive towards social bonds, as well as their maintenance via allegiance behaviors and adherence to group norms and ideologies. On a micro level, affiliation motivates selective bonding among a close-knit number of individuals (e.g. friends, romantic partners). On a macro-level this includes allegiance behaviors such as group pride and nationalism, and the basis for concepts such as ideology.

iii. Status-Seeking: the drive to optimize the individual's relative standing within the group through competition, reputation-enhancement, and the signaling of prestige. Individuals high in social status possess greater ability to influence other group members, e.g. coalesce group motivations to pursue important causes, facilitate adherence to rules, the result of which can further increase affiliative behaviors and the effectiveness of collaboration.

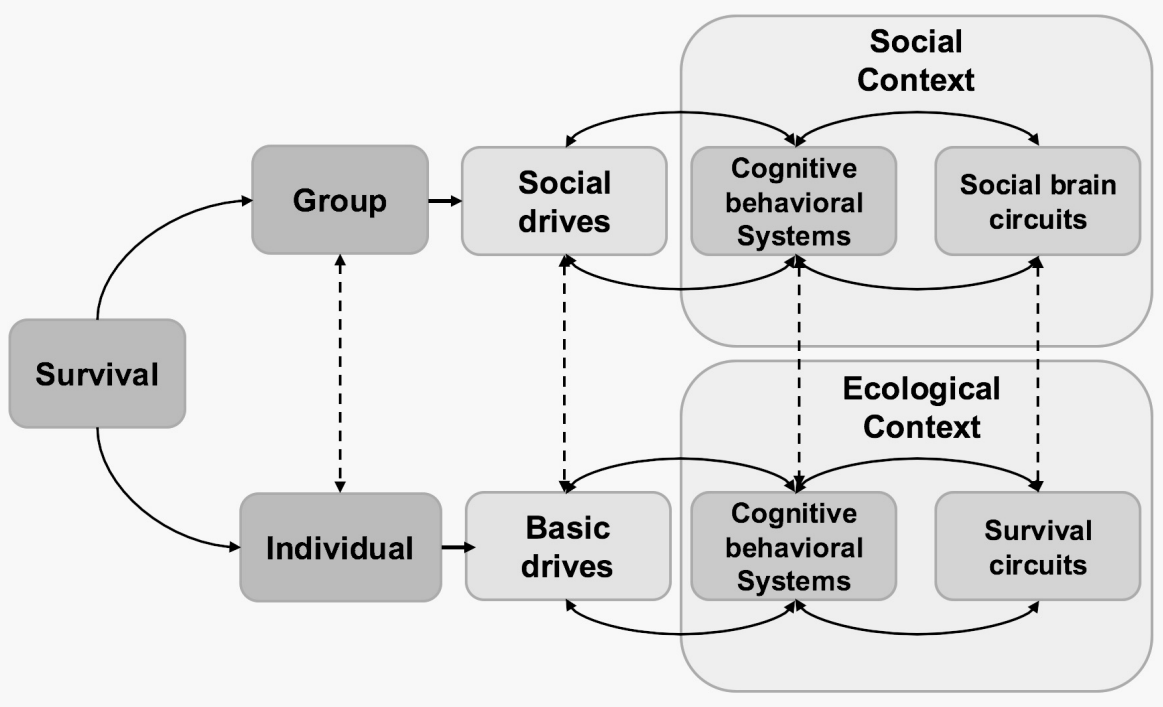

Fig. 2. Survival from social and basic drives. The individual's survival is supported by a set of basic drives including hunger, thirst, reproduction, thermoregulation, anti-predation (e.g. freezing, flight). The evocation of these basic drives is determined by several factors including the ecological context and the internal state of the organism (Mobbs, 2018). These are in turn supported by a set of behavioral, cognitive systems instantiated in survival circuits (see (LeDoux, 2012)). Social drives (e.g. MASS drives) are evoked in group living animals and have a distinct set of neural circuits. These social brain circuits are flexible and interact with basic drives (dotted lines). For example, both basic and social drives can up or down-regulate each other resulting in an interaction between survival circuits and higher level constructive circuits that underlie the social brain.

\section{MASS Linked Affective Dynamics}

As a basic proposition, affect serves a feedback function providing reinforcement or punishment for behavior. Affect encompasses both emotions, the labels given to experienced affect typically with specific origins, and moods, less intense and longer-lasting than emotions but with less obvious causes. Beyond simply tracking progress toward a goal (e.g., negative affect indicates a 


\section{Social and Affective Dynamics and their Survival Benefits}

discrepancy between one's goal and current state), affect energizes behavior (Reeve 2014). In social contexts, observing other's emotions serves as information about what behavior is acceptable (Heerdink et al. 2019). The ability to fulfil MASS drives relies, in part, on affective dynamics (Fig. 3). We propose three such dynamics corresponding with each MASS drive:

i. Reactive flexibility: the ability to change affective content (i.e., anger, happiness) and patterns in response to environmental demands. We propose a role for reactive flexibility in facilitating mutualism. An example of reactive flexibility during mutualism can be seen in shifting from negative to positive affective patterns after the resolution of conflict. Conversely, shifting from positive to negative affect patterns can facilitate mutualism by signaling to the counterpart that their uncooperative behavior is unacceptable to the social group (Granic et al. 2007).

ii. Affective synchrony: the reproduction of another individual's emotions in oneself. Individuals mimic emotions of social counterparts by partially activating the emotional state in themselves (Wood et al. 2016). This synchrony not only enables emotional inference, but also results in greater affiliation effects of collective social engagement (Páez et al. 2015). Synchrony may also promote maintenance of social bonds. For example, neural concordance is higher among closer friends (Hyon, Kleinbaum, and Parkinson 2020) and neural concordance in parentchild dyads enhances development of emotional competence (Lee, Miernicki, and Telzer 2017). Thus, socially proximate individuals may experience synchronous psychological states when exposed to common stimuli resulting in greater perception of affective synchrony thereby strengthening social bonds.

iii. Regulatory flexibility: the ability to use a wide range of regulatory strategies depending on contextual demands, and to monitor and use affective feedback to promote goal pursuit (Bonanno and Burton 2013). Across development, regulatory abilities predict future social skills and social outcomes (Blair et al. 2015), providing opportunity for status attainment and greater future influence. Different emotion regulation strategies confer different benefits. As such, access to distinct strategies facilitates context-dependent selection of emotional responses. Establishment of effortful strategies facilitates increasingly sophisticated and flexible pursuit of temporally distant and difficult goals, like status acquisition (Todd et al. 2012).

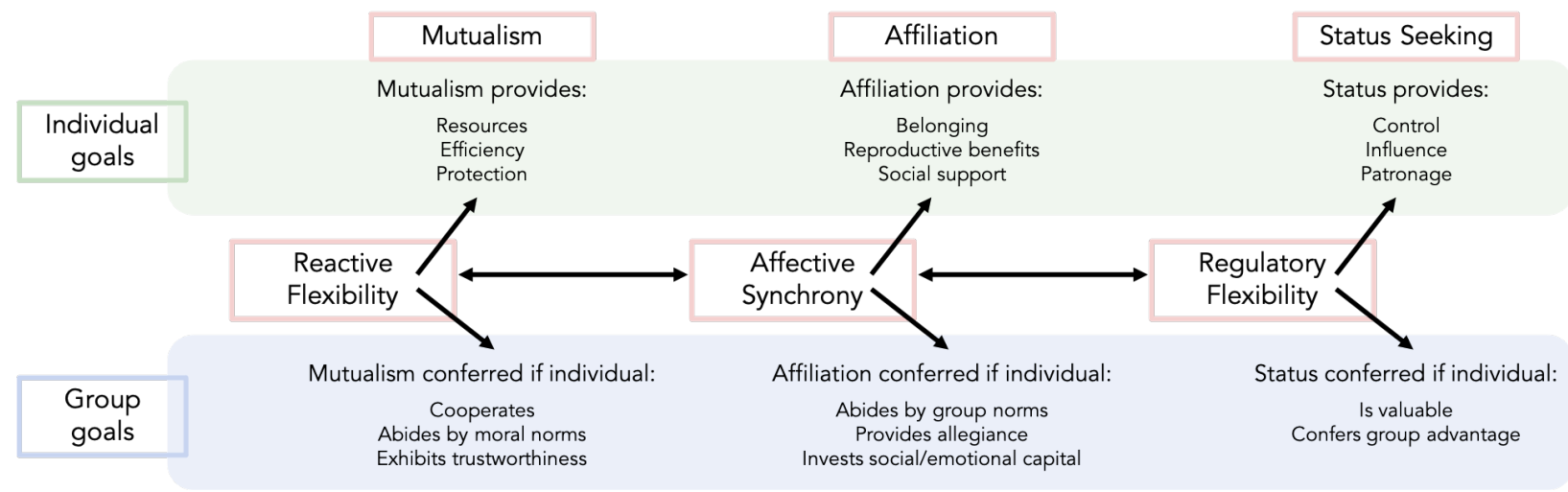




\section{Social and Affective Dynamics and their Survival Benefits}

Fig. 3. Affective dynamics facilitate achievement of individual and group goals for each core social drive. Affective dynamics exert influence on one another such that individuals with high competency in one dynamic (e.g., reactive flexibility) likely have high competence in another (e.g., affective synchrony), thereby compounding the likelihood that they achieve their individual social goals and provide survival benefit to other group members.

Although we propose a role for each affective dynamic within the MASS framework, these dynamics are not mutually exclusive. For example, cooperation generates shared emotional experiences as well as autonomic coupling (Vanutelli et al. 2017), identifying a role for affective synchrony in mutualism. Reactive flexibility is likely linked to social status via trustworthiness: perceived trustworthiness is higher for higher status individuals (Blue et al. 2020) and trustworthiness is associated with affective flexibility (Slepian and Carr 2019). Regulatory flexibility is linked to a myriad of critical facets of successful social functioning including adaptive coping, cognitive control, and physiological regulation(Gross 2015). Ultimately, the shared role of each affective dynamic across the MASS drives demonstrates the interconnected framework supporting these drives despite the separable benefits associated with each.

Although we propose that affective dynamics facilitate core MASS drives, social motives likely also support the evolution of affective dynamics. For each affective dynamic detailed above, bi-directional associations exist with MASS drives such that the survival value of social drives may have helped humans and other emotionally-rich species evolve complex affective systems. All organisms must have the ability to detect and respond to meaningful stimuli in order to survive. Neural systems associated with emotional experiences in humans underpin survival behaviors in humans and non-human animals (LeDoux 2012). Van Kleef proposed in the Emotions As Social Information (EASI) Model that human emotional expressions affect social behavior by triggering affective reactions in others (Van Kleef 2009). Thus, MASS drives likely trigger engagement of certain affective systems to promote similar drive states in group affiliates. Emotions serve an individual function to aid in salience detection, motivation, and attentional allocation (Schwarz and Clore 1983) and also a group function as implicit communication (Oatley and Johnson-laird 1987). The drive for successful social living increase the utility of affective dynamics for survival.

\section{Mutualism}

Wilson and Wilson (D. S. Wilson \& Wilson, 2007) propose that "...for a social group to function as an adaptive unit, its members must do things for each other". Mutualism is defined here as a situation in which individuals gain a net survival benefit from working together (Krebs \& Davies, 1997) and propagates the group's success by minimizing self-serving behaviors. We therefore use the term mutualism to capture several related phenomena including cooperation, reciprocal altruism, symbiosis, and collaboration and synonymous with the term "mutual benefit" associated with +/+ behaviors; see (S. A. West, Griffin, \& Gardner, 2007). Mutualism is a critical aspect of social evolution as it reduces the likelihood of a "Tragedy of the Commons," whereby 


\section{Social and Affective Dynamics and their Survival Benefits}

individuals act selfishly, in turn leading to resource reduction and collapse of society. Mutualism thus relies on reactive flexibility whereby individuals are able to adaptively shift affective states, as well as attention and behavior, in response to shifting group goals (Hollenstein 2015). Mutualism may be distinguished from affiliation through tailoring of affective reactions. Reactive flexibility focuses on the modification of an individual's affective experience to further a common group goal whereas affective synchrony (prioritized for affiliation) is focused on mirroring another's emotions in oneself. Thus, understanding underlying affective dynamics can illuminate where social motives diverge depending on the affective function being prioritized. Not surprisingly, theorists have placed mutualism at the forefront of social brain evolution, which supports identification of and responding to the goals of others. Like other social animals, humans act mutually towards others through resource sharing, helping, cooperative breeding, and offspring protection. Mutualism also begins early in development. For example, human infants will help others at around the age of 14-18 months (Hepach, Vaish, \& Tomasello, 2012). At around 15 months, infants have expectations concerning what is fair (Schmidt \& Sommerville, 2011) and children between the ages of 3 and 8 years demonstrate an aversion to inequality (Fehr et al., 2008). We propose that mutualism takes several broad forms:

\section{Collaboration, Cooperation and Trust}

Haldane (Haldane, 1932) proposed that cooperation occurs when a behavior is "socially valuable, but individually disadvantageous". More recent theorists have proposed the "Interdependence Hypothesis", which posits that collaboration is critical to primate survival and procreation (Tomasello, Melis, Tennie, Wyman, \& Herrmann, 2012). Relatedly, the "Vygotskian Intelligence Theory" suggests that collaboration, communication and social learning are the reasons why primates evolved large brains and complex cognition (Moll \& Tomasello, 2007). Tomasello and colleagues have suggested that human cooperation may have evolved in two key steps. First, during group foraging when hunting individuals were interdependent on each other and therefore cared about each other's welfare. Second, these new collaborative skills were "scaled up" for living in large groups and to face the challenge of competition from other groups (Tomasello et al., 2012). Such dependence on others would presumably increase prosocial behaviors, such as helping others achieve their goals and information sharing (Warneken \& Tomasello, 2009). Mechanistically, the ability to identify and respond flexibility to the goals and affective sharing of others facilitates prosociality through development of empathy and perspective taking (Decety et al. 2016). At a meso level, unique cultural demands may also play a role in shaping the pressures for mutualistic behaviors. For example, Talheim and colleagues showed that the rice growing culture of Southern China, in contrast to the wheat-growing culture of Northern China, is built around interdependence, collaboration and holistic thinking (Talhelm et al., 2014).

Mutualistic behaviors depend on the ability of individuals to determine the likelihood and reliability that others will engage in reciprocal cooperative behaviors. According to Lawler's Affect Theory of Social Exchange, emotional experiences are key for cooperative relationships 


\section{Social and Affective Dynamics and their Survival Benefits}

and act as reinforcements or punishments furthering mutualism (Lawler 2001). Emotions are also subtle external signals about one's intentions. Reactive flexibility enhances the possibility for successful cooperation through the actor's adaptation to the intentions and goals of the social counterpart. High-variability in emotional expression leads to more positive perceptions of authenticity and greater trustworthiness perceptions (Slepian and Carr 2019). Observing others' to determine trustworthiness comes with a time cost, but individuals that develop what McNamara and colleagues call a "social awareness" benefit a group by expediently observing and identifying trustworthy individuals (McNamara, Stephens, Dall, \& Houston, 2009). It is worth noting that perceptions of trustworthiness may not accurately reflect a counterpart's willingness to cooperate, but rather index subjective impressions that garner high consensus (Rule et al. 2013), potentially detection of subtle emotional expressions (Oosterhof and Todorov 2009).

\section{Altruistic and third party punishment}

In order for group living to be successful, cooperation must be enforced by the punishment of defectors and free-riders. Recent evidence suggests that people cooperate at the start of $\mathrm{N}$ Player Prisoner's Dilemma interactions, yet if players defect, collaborators will impose spiteful punishment (Fehr \& Fischbacher, 2003). Likewise, when unfair players receive painful shocks, males, but not females, greet this with feelings of reward (Singer et al., 2006). In some cases, people will punish at a cost to themselves. Known as altruistic punishment, Fehr and Gacthter (Fehr \& Gachter, 2002) have defined this as the situation whereby "individual punish, although the punishment is costly for them and yields no material gain" (p. 137). This is exemplified in the Ultimatum game, in which people will reject unfair offers and even punish at a financial cost to themselves (Guth, Schmittberger, \& Schwarze, 1982; Yu, Calder, \& Mobbs, 2014). Unfair offers induce anger and rejecting unfair relates to reactive aggression in the real world (Gilam et al. 2019). These studies support the notion that a set of punishment norms need to be in place to protect fairness and cooperation and that negative affective experiences can diminish mutualistic behavior after norms are violated. Third-party punishment, or punishment meted out by individuals that observe but are not a party to selfish behaviors results in greater cooperation, but also signals to others by virtue of the cost incurred that one is not selfish (Jordan, Hoffman, Bloom, et al., 2016). This signal is also translated into the perception of trustworthiness, thus justifying the upfront cost given the high moral reputational value assigned by other group members.

\section{Morality and Shared Values}

Humans and nonhuman primates share a set of moral tendencies including a sense of fairness, empathy, forgiveness, and other social emotions that make living in groups a productive enterprise (de Waal, 2011). Moral beliefs are powerful filters that bias information processing and derive as a result of group or cultural norms that develop in relation to collective goals and evolve through time. Once these goals are defined, morality captures the value of actions taken to achieve them. Historically, human cultures made use of institutions of authority such as religions 


\section{Social and Affective Dynamics and their Survival Benefits}

to dictate cultural norms and how these norms were established. These institutions have the advantage of solidifying social bonds among constituents that share in a belief system. Morality is present across human endeavors, where culture plays at times a strong role in tuning the values of individuals that belong to particular groups. Investigation of the neural correlates of moral decision-making reveals a complex, diverse and context specific process that is susceptible to external influences. Crockett has suggested that heuristic, automatic processes, deliberate consequentialist reasoning, and reflexive reasoning coexist in the moral thinking space (Crockett, 2013) while others offer a dynamic rather than a dual-process account (Van Bavel, Feldman Hall, \& Mende-Siedlecki, 2015; Cush_man_2013). Experimental work suggests that individuals that bear a similar neural signature when participating in moral decision-making are remarkably consistent in moral tendencies, indicating that differences in moral preferences can be traced to differences in neural substrate and processing (Kappes, Kahane, \& Crockett, 2016). Thus shared values likely reflect shared or similar neurobiology and the associated affective profiles that motivate reasoning and decision-making processes (Feldman Hall \& Mobbs, 2015). Although disagreement exists as to the role of emotion in mediating morality, lesion and patient studies from cognitive neuroscience link blunted emotion and moral transgression to overlapping deficits in prefrontal systems. This work identifies role of emotion in motivation morally-relevant action (Huebner, Dwyer, and Hauser 2009).

\section{Affiliation}

Theorists have proposed that when coalitions are formed, a new "group mindedness" emerges, creating culture, institutions and social norms (Tomasello et al., 2012). A core feature that arises from group mindedness is the capacity for affiliation. Affiliation can be described as belonging to a social group that shares one's values, beliefs, or goals. The need to affiliate depends on trait level and situational factors. For example, in a classic study, Stanley Schachter showed that when a group of subjects are promised a large shock, compared to a group promised a low shock, they show a strong desire to be with others suggesting that emotional experiences of anxiety or fear promote the need to affiliate (Schachter, 1959). Further work by Sarnoff and Zimbardo suggested that fear increases affiliative behaviors while a reduction is observed in contexts that induce anxiety (Sarnoff \& Zimbardo, 1961). Rofe argued that affiliation behavior depends critically on a predicted cost-benefit calculation, taking into account situational factors, individual traits, and the identity of others with which one may affiliate (Rofe, 1984). Together, these theories suggest that affiliation is closely tied with a psychological need for social support in certain contexts from certain people. More generally, affiliative tendencies may direct decisionmaking process to favor ingroup members, or particular characteristics valued by the individual's culture. For example, different cultural groups assign different value to specific attributes or characteristics, and these differences drive decision-making and behavior (Dolinsky \& Stinerock, 1998). Culture also plays a role in emotional expression. For example, individualist cultures tend to value high arousal emotions (e.g., angry, excited) compared to valuing of low arousal emotions (e.g., relaxed, calm) in collectivist cultures (Lim 2016). These cultural differences are reflected in the frequency with which individuals in different cultures report experiencing certain emotions, 


\section{Social and Affective Dynamics and their Survival Benefits}

which has obvious implications for the way affective synchrony results in a feedback loop that sustains these cultural norms. Even when members are removed geographically from the region of origin, tightly bound cultures assign great importance to social traditions and tend to retain collectivist preferences. In such circumstances, evidence is accumulating that individuals originating from collectivist cultures that continue to adhere to the values espoused by that culture obtain better mental health outcomes (Bhugra, Leff, Mallett, Morgan, \& Zhao, 2010).

\section{Assimilation}

According to Social Identity Theory, individuals have knowledge that they belong to a certain category of group and that self-concept is in part determined by the social group in which they belong (Hogg \& Abrams, 1988; Tajfel \& Turner, 1986). These extend from dialect, accent, and attire, where groups "police" their boundaries against out-group members by using "badges" for in-group membership. Individuals also engage in automatic mimicry which gives rise to emotional contagion, a form of affective assimilation (Prochazkova and Kret 2017). A natural tendency towards imitation of in-group members is evident from an early age (Buttelmann, Zmyj, Daum, \& Carpenter, 2013) and most obvious in adolescence during which highly differentiated style and behavior are propagated by the group members attempting to find acceptance in the group. Fitting into the group is a complex process observed across cultures and socioeconomic status in adolescents trying to find their place in the world. Such ephemeral fashion changes also occur in language, including the appearance of new words and expressions to reflect the youth culture or sub-culture. These fashions are facilitated by skin color, geography, territory, and dialect with the common goal of showing that "I belong to this group".

\section{Belonging}

Social belonging developed based on the importance of group membership as a critical force in survival during human evolutionary history, and is a powerful motivational factor in social behaviors, thoughts, and perception (Baumeister \& Leary, 1995). The need to belong is agnostic to culture, though individualist and collective cultures differ in terms of number and closeness of relationships (Verkuyten \& Masson, 1996). Cultural differences in group goals have evolved significantly to encompass non-survival ends in modern contexts, however the basic social motivation of belonging continues to drive conformation of belief and behavior, and the consideration of others' reactions in contemplating our own choices. The need to belong motivates the formation of attachment and interpersonal relationships that provide a sense of acceptance, and a reciprocal value relationship between the individual and group. Belonging provides and affirms a sense of identity, security, and self-worth, all of which contribute to the maintenance of positive affective equilibrium. Positive affect in turn has beneficial health consequences due to associations with protective psychosocial factors like social connectedness (Steptoe, Dockray, and Wardle 2009). Lambert et al showed in a series of studies that belonging, more so than social support or social value, provides a greater sense of perceived meaningfulness of life (Lambert et al., 2013). An individual is willing to invest emotional and social 


\section{Social and Affective Dynamics and their Survival Benefits}

capital into the group in the form of assistance and cooperation so long as the goals of others align with those of the individual, thus enhancing the meaning associated with participating in these activities. Ostracism from the group can result in seemingly counterintuitive selfpreservation attempts to reduce the emotional distress that results from a potential loss of belonging (Woodyatt and Wenzel 2013). The need to belong is so strong that in some cases individuals will signal group loyalty even when such signaling ignores certain acquisition of higher value for departing from the status quo. While superficially irrational, such behavior is socially motivated, consistent with a group identity, and hence perfectly rational under the social value construct. In order for social groups to function effectively, e.g. facilitate cooperation, trust must be established. Belonging and resulting social identity, together with a system of rewards and punishments, are the binding agents that hold group trust together. Emotions are one way the individual and the group determine who intends to abide by the social contract.

\section{Allegiance and In-Group Favoritism}

Allegiances work to bind the group, give it purpose, pride, solidarity, identity, and prestige. Allegiances can lead to greater commitment to the group and decreased desire to depart from the group even when it is disadvantageous to remain (Ellemers, Spears, \& Doosje, 1997). Likewise, in-group favoritism can be seen as a primary means of reinforcing group solidarity and indeed represents one of the most well-demonstrated phenomena in social psychology. The ease and rapidity with which this group bias emerges is attested by a variety of research employing Tajfel's minimal group paradigm, in which subjects exhibit in-group favoritism despite knowledge that the relevant groups have been arbitrarily or randomly devised (M. Brewer, 1979; Diehl, 1990). Utilizing evidence from the minimal group paradigm, Tajfel and Turner (Tajfel \& Turner, 1986) proposed that the individual's self-concept is shaped by the social group to which the individual believes they belong. In order to maintain a positive self-concept via their social identities, group members are thus motivated to arrive at favorable comparisons between their in-groups and salient out-groups. In-group members may arrive at conclusions motivated by directionality as opposed to accuracy and at the expense of being correct to signal loyalty. While seemingly maladaptive, this common behavior is rational from the context of reputational benefits that may be received within one's group. Some theorists, however, suggest that distinctly positive in-group evaluations are rooted not in socially-derived self-enhancement motives, but rather in the security and trust associated with in-group encounters, thus stressing a tie to mutualism (Brewer, 2007).

\section{Selective Bonding}

The maintenance and seeking of social bonds is one of the most powerful humans drives. Baumeister and Leary (Baumeister \& Leary, 1995) have also proposed the Belongingness Hypothesis where humans have an inherent drive "for and to maintain at least a minimum quantity of lasting, positive interpersonal relationships" (p497). Supporting their importance, Baumeister and Leary have pointed out that poor social bonds can lead to negative affect, poor 


\section{Social and Affective Dynamics and their Survival Benefits}

health, social adjustment and quality of life. We propose that bonding can be separated into several categories including attachment between the parent and the child, romantic love, or tight allegiances among a small group of friends. Bonding can be distinguished from belonging in that a need to belonging motivates bonding, but bonding as we define it is more selective and reciprocal.

Attachment. Selective bonding is most evident when examining the relationship between a mother and infant. Bowlby (Bowlby, 1988) maintained that attachment between the mother and infant is critical to healthy socialization. This is supported by the profound negative effects of maternal deprivation on non-human primates (Harlow, 1958) and studies conducted on human children raised in orphanages (Bowlby, 1988; Telzer et al., 2013). Affective synchrony is an important feature of mother-child interactions, encompassing both the mother's and the child's responsivity and emotional capacity to flexibly respond to the other (Leclère et al. 2014). Synchrony in these bonded relationships differs from mirroring or the chameleon effect in part because it involves matching of emotional states. The ability to effectively respond in this crucial dyad has a myriad of implications for later development, including regulatory abilities, which can influence a child's later ability to engage in social groups outside of the family unit (Harrist and Waugh 2002). Mother-infant bonds may be facilitated at the hormonal level by oxytocin, which has been found to increase during mother-infant bonding (Ross \& Young, 2009). Further, the administration of an oxytocin agonist promotes maternal behavior in virgin sheep (Kendrick, 2004), while an oxytocin antagonist inhibits such behavior (van Leengoed, Kerker, \& Swanson, 1987). Along with candidate genes such as Grb10 (Garfield et al., 2011), OXTR (Pedersen, Vadlamudi, Boccia, \& Amico, 2006), vasopressin, and the mu-opioid receptor gene OPRM1 (Moles, Kieffer, \& D'Amato, 2004), mother-infant bonding is presumably innate and critical to the healthy development and survival of offspring. Abnormal social development, including autism, has been proposed to be linked with atypical levels of oxytocin and vasopressin, the latter being linked with sensory processing (Carson et al., 2015). The capacity for normal social behaviors may develop and manifest due to a coordinated timing of signals in specific pathways, and begin with attachment to parents or caretakers.

i. Friendship and Social Networks. Enduring friendships are observed across a number of species including elephants, dolphins and chimpanzees (Seyfarth \& Cheney, 2012). In humans, the formation of friendships is a common and highly adaptive social behavior. Baumeister and Leary (Baumeister \& Leary, 1995) propose that people seek out relationships at least to the point that satisfies an individual minimum threshold level of social contact and relationships, even in the absence of identifiable extrinsic incentives. Goals, achievements, and experiences are imbued with meaning when they can be witnessed and shared with others in one's social circle. Until the age of 12, friendships may be fleeting, yet individuals above this age tend to form longterm friendships and become emotionally close, even if they are physically distant (Selman, 1980; Selman \& Schultz, 1990). Dunbar (Dunbar, 1993; Dunbar, 2010) has proposed a cognitive limit to the number of people with whom one can maintain stable relationships, which likely evolved when social groups were much smaller. Dunbar's number is placed at approximately 150 friends, 


\section{Social and Affective Dynamics and their Survival Benefits}

around 15 of who are very close. Social structure features of modern societies are similar to those observed in Hunter-Gather societies (Apicella, Marlowe, Fowler, \& Christakis, 2012), suggesting that these structures may have evolved early in human history, perhaps during shared hunts and cooked meals (E. Wilson, 2012).

ii. Romantic Love. Love is arguably the strongest human bond between non-kin. When reciprocated, love floods the individual with ecstasy, while unrequited love may result in feelings of extreme sadness and despair (Hatfield \& Rapson, 1993). Love elicits different emotions depending on the situation. Recognizing and matching a romantic counterpart's emotional expression is, in part, what separates reciprocated and unrequited love. Brain imaging studies show that viewing images of a loved one results in increased activity in the brain reward and opioid systems (Aron et al., 2005), yet rejection by loved ones activates the brain pain systems (Kross, Berman, Mischel, Smith, \& Wager, 2011). Individuals in romantic relationships demonstrate greater regulatory control during negative emotions (Song et al. 2016), which may be one mechanism underlying successful bonding. Romantic love begins in adolescence:, approximately $25 \%$ of females begin dating by age 13 , increasing to $75 \%$ by age 15 (ZimmerGembeck, 2002). In adults, love may result in longer-term commitment such as marriage, which sets rules on morally appropriate behavior and is often tied to cultural and religious dogma.

\section{Status Seeking}

While status can be defined as an individual's group standing founded on honor, prestige and deference (Berger, Cohen, \& Zelditch, 1972) others have defined it simply as respect and admiration (Leary, Jongman-Sereno, \& Diebels, 2014) or superiority (Adler, 1930). No matter how we define it, there seems to be a human drive for high status (Anderson, Hildreth, \& Howland, 2015). One reason is that status has been perceived as a valuable resource, which yields direct utility to the individual (Huberman, Loch, \& Onculer, 2004). In the Paleolithic period, status was given to tribe members with the best hunting skills as this was critical to the survival of the group (Ellis, 1993). Status objects such as jewelry soon evolved and go back 50,000 years acting as static markers of authority (Diamond, 1997). In modern contexts luxurious goods such as wristwatches and cars indicate high social status (Frank, 1999), and these are indicative of higher SES including financial wealth, education, and occupational prestige, yet may have no value other than to signal status. Affectively, pride is a major motivator for status-seeking (Cheng, Tracy, and Henrich 2010) and can signal status achievement through pride displays (e.g., posture, strutting). External displays of pride are likely innate given evidence that congenitally blind humans physically respond to success similar to sighted individuals (Tracy \& Matsumoto, 2008). Notable differences exist in displays of failure among sighted and congenitally blind individuals suggesting sighted individuals may suppress low-status displays. Nonverbal expressions of pride are identified by young children (Tracy et al., 2005) across a range of cultures (Tracy \& Robins, 2008), again supporting the assertion that status serves an important function in social groups. 


\section{Social and Affective Dynamics and their Survival Benefits}

\section{Status as Social "Currency"}

Social status has been proposed as a valuable resource yielding direct utility to the individual (Huberman et al., 2004). Some have noted that the drive to maintain a favorable image amongst peers, even strangers, may result in seemingly irrational and self-harmful choices, such as the sacrifice of tangible rewards. This phenomenon is referred to as "face-work" (Brown, 1968) and may extend to third-party instances in which people are even willing to incur a debt to acquire information about high-ranking individuals (e.g. celebrity gossip magazines). Interestingly, similar behaviors have been observed in rhesus macaques, who will sacrifice access to a palatable fluid in order to view images of high-status monkeys, yet require fluid overpayment in return for viewing low-status monkeys (Deaner, Khera, \& Platt, 2005). Evidence for the valuation of social status as a distinct "currency" in humans is further provided by investigations of the "winner's curse", or the tendency of individuals to bid more during auctions than prescribed by normative economic principles (van den Bos et al., 2008). For example, Delgado et al (Delgado, Schotter, Ozbay, \& Phelps, 2008) have suggested that the social nature of auctions-specifically, the fear of losing in a social context-is a significant origin of overbidding practices. Rather than mere valuation anomalies, these findings may be understood in terms of a "common currency" that conveys social standing benefits as it does material ends. Indeed social standing may yield material benefits, and attract resources and loyalty if maintained and effectively signaled over time, discussed further below. Beyond tangible rewards, high-status may be intrinsically rewarding and is associated with increased dopamine receptor binding in humans (Martinez et al. 2010) and non-human primates (Morganet_al. 2002).

\section{Status Signaling and Conspicuous Consumption}

The drive to signal superiority is not a feature unique to humans but manifests across species, ranging from the display of the peacock's tail and flashing of fireflies to the decorated recesses of the bowerbird and boisterous song of cicadas (Zehavi \& Zahavi, 1997). According to sexual selection accounts, these elaborate displays confer a reproductive advantage by making apparent to the opposite sex favorable qualities (e.g. wealth, physical superiority) that boost the organism's odds of being selected as a mate (Collins, Baer, \& Weber, 2015; De Fraja, 2009). Humans are no different. It has been suggested that charities commonly announce donors' names in order to accommodate the reputation building strategies that are presumed to motivate contributions-termed "conspicuous compassion" (Engelmann \& Fischbacher, 2009; P. West, 2004). Like otherwise costly reputation-building strategies which rely upon public consumption for their reward and evolution (Nowak, 2006; Tennie, Frith, \& Frith, 2010), high rank and prestige must be signaled to the group in order to derive the full benefits of their attainment. Highlighting this, the sociologist and economist Thorstein Veblen (Veblen, 1899) coined the term "conspicuous consumption" to refer to purchase behaviors driven principally by their ability to convey the owner's status and prestige. Veblen's notion was thus among the first to emphasize the social, rather than purely utilitarian, origins of consumer decision-making processes (Memushi, 2014). As Mason (Mason, 1984): "To the purely conspicuous consumer, the 


\section{Social and Affective Dynamics and their Survival Benefits}

satisfaction derived from any particular purchase comes not from its value in use but from audience reaction to the wealth displayed by the purchaser in being able to secure the product for 'consumption'" (p. 26). Beyond vast economic purchases and ostensible goods, social prestige may also be represented in the form of other culturally-attuned behaviors.

\section{Value Seeking and Reputation Management}

It has long been known by economists that consumption behaviors are driven by the social recognition or need to please one's peers. Fiske also argues that the transfer of material "things" between people results in the highest-ranking individuals having more of better "things". Indeed, Campbell-Meiklejohn and colleagues (Campbell-Meiklejohn, Bach, Roepstorff, Dolan, \& Frith, 2010) showed that the value of an object is determined by how others valued it. Humans are status maximizers and status is often acquired in complex ways. For example, people prefer to relay positive information (Rosen, 1970) and weigh their advice more carefully when it reflects on them directly rather than through the medium of a third-party (Jonas, Schulz-Hardt, \& Frey, 2005). One interpretation is that people like to yield information to others, particularly if it shines them in a positive light. Fitting with this idea, Anderson and Kildiff (Anderson \& Kilduff, 2009) propose that status-seekers seek high status in an attempt to make themselves appear more important to the group, and this pursuit of values may be universal. Finally, behavioral and brain imaging work demonstrate that individuals report feeling more rewarded and show increased activity in the brain's reward circuitry when observing others win money when winning is based on their advice compared to winning based on another's advice (Mobbs et al., 2015). This supports a large body of research showing that reflected glory is a powerful form of social value seeking.

Studies across psychology and behavioral economics have long demonstrated that the individual's actions are critically shaped by the mere presence of others. Often, such "audience effects" reflect the individual's attempt to optimize their representation to fellow group members - a behavior referred to as reputation or impression management, and which has been delineated further in terms of separate motivation and construction components (Leary \& Kowalski, 1990; Tennie et al., 2010). As Leary and Kowalski (1990) note, impression motivation and construction processes often operate outside the actor's conscious awareness, thus stressing the deep-seated and automatic nature of the drive to project a favorable self-image to the group. Reputation-enhancing behaviors, such as charitable donations, have widely been shown to increase under conditions of social observation (Izuma, Saito, \& Sadato, 2010) or even cues of observation (e.g. eyespots; (Haley \& Fessler, 2005). Banerjee (Banerjee, 2002) has shown that self-representation behavior begins in children around the age of 8 years, while others suggest that this occurs much earlier. For example, 5- to 6-year-olds act more prosocially when they are observed or think they are being observed (J. M. Engelmann, Herrmann, \& Tomasello, 2012; Piazza, Bering, \& Ingram, 2011). Similar findings have been observed in non-human animalsmost notably the cleaner fish, which displays increased cooperative behavior with client fish when other watchful, or "image-scoring", clients are present (Bshary \& Grutter, 2006). 


\section{Social and Affective Dynamics and their Survival Benefits}

\section{Competition}

A key arena for status seeking is competition. Humphrey (Humphrey, 1976) proposes that primate cognition is due to social competition, which by definition includes a drive to perform better than others in the group. Likewise, Deutsch (Deutsch, 1949) suggested that in situations in which two or more people are attempting to attain a common goal in a zero sum environment, one agent will win as a result of the failure of others. Competition is a dominant ecological force in natural selection (Diamond, 1978) and evolutionary biologists typical explain competition through the lens of sexual selection and dominance hierarchies where organisms fight for leadership of the group. Social comparison is an important source of competitive behavior that influences self-perceptions via emotional reactions (Garcia, Tor, and Schiff 2013). The Ecological Dominance-Social Competition Model (EDSC; Flinn et al., 2005) suggests that neural connections between emotion and higher-cognition centers in the brain provide a biological basis in humans for status-attaining skills like social empathy, self-awareness, and theory of mind. Strategic behavior key for competitive success involves mental simulations that include emotional responses (Damasio et al. 2000). Emotional responses act as a source of feedback indicating the value of the goal and the potential of achieving it (Baumeister et al. 2007). Importantly, regulating emotions involves bidirectional modulation depending on needs. Upregulation of negative emotions like anger can facilitate long-term goals such as enhancing status via competition (Tamir 2009).

\section{Linking drives to group living success and survival}

The MASS drives proposed here are believed to facilitate group formation, stability, individual, and group success and map directly onto survival benefits (Fig. 1). While the MASS motives provide a general framework from which to explain behaviors that facilitate group living, we proposed that (i) mutualism increases shared goals, collaboration, and increases collective intelligence; (ii) affiliation results in stronger group ties and identity and will facilitate in/out group competition. Furthermore, the stronger the affiliation, the more likely affiliates will protect you, share food, collaborate, share information, and provide social support; (iii) status seeking enhances the likelihood that one would acquire the best mates, better protection from threat, provide first and access to information, and increased life quality and social support. It is also important to note that MASS motives do not work in isolation. For example, status seeking can be associated with increasing one's reputation as a good collaborator. A positive reputation and the benefits that obtain from maintaining such status may contribute to and increase mutualistic behaviors. The material and immaterial benefits (e.g. social support) that derive from cooperation reinforce such group behaviors resulting in greater probability of both individual and group survival. Affiliation through social bonds may also be the first step to allegiance and relate to both increases in status and mutualism. 


\section{Social and Affective Dynamics and their Survival Benefits}

Affective dynamics of reactive flexibility, affective synchrony, and emotional intelligence are proposed to facilitate attainment of MASS drives. These skills signal that one can provide benefit to the social group if included. The ability to respond to shifting social demands increases mutualism because of increased perceived trustworthiness (Slepian and Carr 2019). Demonstrating emotional correspondence with social counterparts increases affiliation through intensification of group experiences (Páez et al. 2015). Competently regulating emotional experiences lays the foundation for status attainment through effective external displays (Shariff and Tracy 2009). Understanding how each MASS drive contributes to survival motivation can reveal distinct features of corresponding affective dynamics. For example, affective synchrony may facilitate affiliation but may undermine status-seeking.

The MASS model posits that a specific set of social behaviors facilitates a symbiotic arrangement at the local (interpersonal) and global (group) level and that shapes motivational processes to remain in the relationship given the psychological, material, survival, and other benefits that accrue due to the circular model. At the local level the costs incurred, typically time and effort to forge and maintain interpersonal relationships and perform functions in service of a group interest, will often yield a return that is both rewarding and meaningful to the individual. In some circumstances the rewards are not obvious or apparent, however when viewed at the global level, efforts may contribute to a pool of resources that serves as an emergent good for both the individual and group, e.g. collective intelligence, greater opportunities, optimization of skill application. Each of these increases the efficiency and flexibility of the species, thus imbuing a survival value to prosocial behavior.

\section{Concluding Remarks}

The human brain is wired for sociality, yet when investigating the social brain, researchers have focused on the cognitive operations rather than what drives sociality. Our theory proposes that the dynamics between MASS drives are founded on three chief premises: (i) living in groups provides fitness benefits; (ii) these benefits have resulted in a set drives that need to be satisfied for successful group living; and (iii) these drives are optimized by a set of evolved social behaviors, affective dynamics, and neurocognitive systems that facilitate group formation and enhance value and status in the group. With this theory, we can begin to unify social neuroscience with the related fields of anthropology, social psychology, affective science, sociology, and evolutionary biology. For example, MASS drives provide a universal account for why it is painful to be ostracized, why it is rewarding to be praised, why status is a driving force across many activities, why we feel the need to belong, why we conform, why we feel group pride, and why we experience out-group bias. Like any model, empirical predictions and falsifiability are required to adjudicate its usefulness. Our theory predicts that garnering other's respect should be rewarding, people should attempt to hide their weaknesses and promote their strengths, that people should act differently when interacting with higher or lower status individuals, and that the inability to optimize MASS drives will result in lower status, rejection, isolation, and, in turn, these hardships will lead to a significant reduction in access to all the 


\section{Social and Affective Dynamics and their Survival Benefits}

benefits of group living. Cooperation and collaboration should yield group benefits that, when made available to all group members, improve individual wellbeing, and increase survivability. Many of these questions have already been tested, yet the burgeoning field of social psychology and social neuroscience will further clarify the value of social behavior. 


\section{Social and Affective Dynamics and their Survival Benefits}

\section{References}

Barrett, Lisa Feldman, James Gross, Tamlin Conner Christensen, and Michael Benvenuto. 2001. "Knowing What You're Feeling and Knowing What to Do about It: Mapping the Relation between Emotion Differentiation and Emotion Regulation." Cognition and Emotion 15(6):713-24. doi: 10.1080/02699930143000239.

Baumeister, Roy F., and Mark R. Leary. 1995a. "The Need to Belong: Desire for Interpersonal Attachments as a Fundamental Human Motivation." Psychological Bulletin 117(3):497-529. doi: http://dx.doi.org/10.1037/0033-2909.117.3.497.

Baumeister, Roy F., and Mark R. Leary. 1995b. "The Need to Belong: Desire for Interpersonal Attachments as a Fundamental Human Motivation." Psychological Bulletin 117(3):497-529. doi: 10.1037/0033-2909.117.3.497.

Baumeister, Roy F., Kathleen D. Vohs, C. Nathan DeWall, and Liqing Zhang. 2007. "How Emotion Shapes Behavior: Feedback, Anticipation, and Reflection, Rather Than Direct Causation." Personality and Social Psychology Review 11(2):167203. doi: $10.1177 / 1088868307301033$.

Blair, Bethany L., Nicole B. Perry, Marion O'Brien, Susan D. Calkins, Susan P. Keane, and Lilly Shanahan. 2015. "Identifying Developmental Cascades among Differentiated Dimensions of Social Competence and Emotion Regulation." Developmental Psychology 51(8):1062-73. doi: 10.1037/a0039472.

Blue, Philip R., Jie Hu, Lu Peng, Hongbo Yu, Huiying Liu, and Xiaolin Zhou. 2020. "Whose Promises Are Worth More? How Social Status Affects Trust in Promises." European Journal of Social Psychology 50(1):189-206. doi: https://doi.org/10.1002/ejsp.2596.

Bonanno, George A., and Charles L. Burton. 2013. "Regulatory Flexibility: An Individual Differences Perspective on Coping and Emotion Regulation." Perspectives on Psychological Science 8(6):591-612. doi: 10.1177/1745691613504116.

Cheng, Joey T., Jessica L. Tracy, and Joseph Henrich. 2010. "Pride, Personality, and the Evolutionary Foundations of Human Social Status." Evolution and Human Behavior 31(5):334-47. doi: 10.1016/j.evolhumbehav.2010.02.004.

Cottrell, Catherine A., and Steven L. Neuberg. 2005. "Different Emotional Reactions to Different Groups: A Sociofunctional Threat-Based Approach to 'Prejudice.'" 


\section{Social and Affective Dynamics and their Survival Benefits}

Journal of Personality and Social Psychology 88(5):770-89. doi: 10.1037/00223514.88.5.770.

Cushman, Fiery. 2013. "Action, Outcome, and Value: A Dual-System Framework for Morality." Personality and Social Psychology Review 17(3):273-92. doi: 10.1177/1088868313495594.

D, Morgan, Grant Ka, Gage Hd, Mach Rh, Kaplan Jr, Prioleau O, Nader Sh, Buchheimer $\mathrm{N}$, Ehrenkaufer Rl, and Nader Ma. 2002. "Social Dominance in Monkeys: Dopamine D2 Receptors and Cocaine Self-Administration." Nature Neuroscience 5(2). Retrieved December 1, 2020 (https://pubmed.ncbi.nlm.nih.gov/11802171/).

Damasio, Antonio R., Thomas J. Grabowski, Antoine Bechara, Hanna Damasio, Laura L. B. Ponto, Josef Parvizi, and Richard D. Hichwa. 2000. "Subcortical and Cortical Brain Activity during the Feeling of Self-Generated Emotions." Nature Neuroscience 3(10):1049-56. doi: 10.1038/79871.

Decety, Jean, Inbal Ben-Ami Bartal, Florina Uzefovsky, and Ariel Knafo-Noam. 2016. "Empathy as a Driver of Prosocial Behaviour: Highly Conserved Neurobehavioural Mechanisms across Species." Philosophical Transactions of the Royal Society B: Biological Sciences 371(1686). doi: 10.1098/rstb.2015.0077.

Deci, E. L., R. Koestner, and R. M. Ryan. 1999. "A Meta-Analytic Review of Experiments Examining the Effects of Extrinsic Rewards on Intrinsic Motivation."

Psychological Bulletin 125(6):627-68; discussion 692-700. doi: 10.1037/00332909.125.6.627.

Garcia, Stephen M., Avishalom Tor, and Tyrone M. Schiff. 2013. "The Psychology of Competition: A Social Comparison Perspective." Perspectives on Psychological Science. doi: 10.1177/1745691613504114.

Gilam, Gadi, Rany Abend, Hagai Shani, Ziv Ben-Zion, and Talma Hendler. 2019. "The Anger-Infused Ultimatum Game: A Reliable and Valid Paradigm to Induce and Assess Anger." Emotion 19(1):84-96. doi: 10.1037/emo0000435.

Granic, Isabela, Arland O'Hara, Debra Pepler, and Marc D. Lewis. 2007. "A Dynamic Systems Analysis of Parent-Child Changes Associated with Successful 'RealWorld' Interventions for Aggressive Children." Journal of Abnormal Child Psychology 35(5):845-57. doi: 10.1007/s10802-007-9133-4. 


\section{Social and Affective Dynamics and their Survival Benefits}

Gross, James J. 1998. "Sharpening the Focus: Emotion Regulation, Arousal, and Social Competence." Psychological Inquiry 9(4):287-90. doi: 10.1207/s15327965pli0904_8.

Gross, James J. 2015. "Emotion Regulation: Current Status and Future Prospects." Psychological Inquiry 26(1):1-26. doi: 10.1080/1047840X.2014.940781.

Harrist, Amanda W., and Ralph M. Waugh. 2002. "Dyadic Synchrony: Its Structure and Function in Children's Development." Developmental Review 22(4):555-92. doi: 10.1016/S0273-2297(02)00500-2.

Heerdink, Marc W., Lukas F. Koning, Evert A. van Doorn, and Gerben A. van Kleef. 2019. "Emotions as Guardians of Group Norms: Expressions of Anger and Disgust Drive Inferences about Autonomy and Purity Violations." Cognition and Emotion 33(3):563-78. doi: 10.1080/02699931.2018.1476324.

Hollenstein, Tom. 2015. "This Time, It's Real: Affective Flexibility, Time Scales, Feedback Loops, and the Regulation of Emotion." Emotion Review 7(4):308-15. doi: 10.1177/1754073915590621.

Huebner, Bryce, Susan Dwyer, and Marc Hauser. 2009. "The Role of Emotion in Moral Psychology." Trends in Cognitive Sciences 13(1):1-6. doi: 10.1016/j.tics.2008.09.006.

Hyon, Ryan, Adam M. Kleinbaum, and Carolyn Parkinson. 2020. "Social Network Proximity Predicts Similar Trajectories of Psychological States: Evidence from Multi-Voxel Spatiotemporal Dynamics." Neurolmage 216:116492. doi: 10.1016/j.neuroimage.2019.116492.

Jordan, Peter J., and Ashlea C. Troth. 2004. "Managing Emotions During Team Problem Solving: Emotional Intelligence and Conflict Resolution." Human Performance 17(2):195-218. doi: 10.1207/s15327043hup1702_4.

Kashdan, T., L. Barrett, and Patrick E. McKnight. 2015. "Unpacking Emotion Differentiation." doi: 10.1177/0963721414550708.

van Kleef, Gerben A., Arik Cheshin, Agneta H. Fischer, and Iris K. Schneider. 2016. "Editorial: The Social Nature of Emotions." Frontiers in Psychology 7. doi: 10.3389/fpsyg.2016.00896.

Lawler, Edward J. 2001. "An Affect Theory of Social Exchange." American Journal of Sociology 107(2):321-52. doi: 10.1086/324071. 


\section{Social and Affective Dynamics and their Survival Benefits}

Leclère, Chloë, Sylvie Viaux, Marie Avril, Catherine Achard, Mohamed Chetouani, Sylvain Missonnier, and David Cohen. 2014. "Why Synchrony Matters during Mother-Child Interactions: A Systematic Review." PLOS ONE 9(12). doi: 10.1371/journal.pone.0113571.

LeDoux, Joseph E. 2012. "EVOLUTION OF HUMAN EMOTION." Progress in Brain Research 195:431-42. doi: 10.1016/B978-0-444-53860-4.00021-0.

Lee, Tae-Ho, Michelle E. Miernicki, and Eva H. Telzer. 2017. "Families That Fire Together Smile Together: Resting State Connectome Similarity and Daily Emotional Synchrony in Parent-Child Dyads." Neurolmage 152:31-37. doi: 10.1016/j.neuroimage.2017.02.078.

Lim, Nangyeon. 2016. "Cultural Differences in Emotion: Differences in Emotional Arousal Level between the East and the West." Integrative Medicine Research 5(2):105-9. doi: 10.1016/j.imr.2016.03.004.

Lopes, Paulo N., Marc A. Brackett, John B. Nezlek, Astrid Schütz, Ina Sellin, and Peter Salovey. 2004. "Emotional Intelligence and Social Interaction." Personality and Social Psychology Bulletin 30(8):1018-34. doi: 10.1177/0146167204264762.

Martinez, Diana, Daria Orlowska, Rajesh Narendran, Mark Slifstein, Fei Liu, Dileep Kumar, Allegra Broft, Ronald Van Heertum, and Herbert D. Kleber. 2010. "Dopamine Type 2/3 Receptor Availability in the Striatum and Social Status in Human Volunteers." Biological Psychiatry 67(3):275-78. doi: 10.1016/j.biopsych.2009.07.037.

Mavroveli, Stella, K. V. Petrides, Carolien Rieffe, and Femke Bakker. 2007. "Trait Emotional Intelligence, Psychological Well-Being and Peer-Rated Social Competence in Adolescence." British Journal of Developmental Psychology 25(2):263-75. doi: https://doi.org/10.1348/026151006X118577.

Oatley, Keith, and P. N. Johnson-laird. 1987. "Towards a Cognitive Theory of Emotions." Cognition and Emotion 1(1):29-50. doi: 10.1080/02699938708408362.

Oosterhof, Nikolaas N., and Alexander Todorov. 2009. "Shared Perceptual Basis of Emotional Expressions and Trustworthiness Impressions from Faces." Emotion 9(1):128-33. doi: 10.1037/a0014520. 


\section{Social and Affective Dynamics and their Survival Benefits}

Páez, Dario, Bernard Rimé, Nekane Basabe, Anna Wlodarczyk, and Larraitz Zumeta. 2015. "Psychosocial Effects of Perceived Emotional Synchrony in Collective Gatherings." Journal of Personality and Social Psychology 108(5):711-29. doi: 10.1037/pspi0000014.

Prochazkova, Eliska, and Mariska E. Kret. 2017. "Connecting Minds and Sharing Emotions through Mimicry: A Neurocognitive Model of Emotional Contagion." Neuroscience \& Biobehavioral Reviews 80:99-114. doi: 10.1016/j.neubiorev.2017.05.013.

Reeve, Johnmarshall. 2014. Understanding Motivation and Emotion. John Wiley \& Sons.

Rule, Nicholas O., Anne C. Krendl, Zorana Ivcevic, and Nalini Ambady. 2013. "Accuracy and Consensus in Judgments of Trustworthiness from Faces: Behavioral and Neural Correlates." Journal of Personality and Social Psychology 104(3):409-26. doi: 10.1037/a0031050.

Salovey, Peter, and John D. Mayer. 1990. "Emotional Intelligence." Imagination, Cognition and Personality 9(3):185-211. doi: 10.2190/DUGG-P24E-52WK6CDG.

Schwarz, Norbert, and Gerald L. Clore. 1983. "Mood, Misattribution, and Judgments of Well-Being: Informative and Directive Functions of Affective States." Journal of Personality and Social Psychology 45(3):513-23. doi: 10.1037/00223514.45.3.513.

Shariff, Azim F., and Jessica L. Tracy. 2009. "Knowing Who's Boss: Implicit Perceptions of Status from the Nonverbal Expression of Pride." Emotion 9(5):631-39. doi: 10.1037/a0017089.

Slepian, Michael L., and Evan W. Carr. 2019. "Facial Expressions of Authenticity: Emotion Variability Increases Judgments of Trustworthiness and Leadership." Cognition 183:82-98. doi: 10.1016/j.cognition.2018.10.009.

Song, Sensen, Zhiling Zou, Hongwen Song, Yongming Wang, Federico d'Oleire Uquillas, Huijun Wang, and Hong Chen. 2016. "Romantic Love Is Associated with Enhanced Inhibitory Control in an Emotional Stop-Signal Task." Frontiers in Psychology 7. doi: 10.3389/fpsyg.2016.01574. 


\section{Social and Affective Dynamics and their Survival Benefits}

Steptoe, Andrew, Samantha Dockray, and Jane Wardle. 2009. "Positive Affect and Psychobiological Processes Relevant to Health." Journal of Personality 77(6):1747-76. doi: https://doi.org/10.1111/j.1467-6494.2009.00599.x.

Tamir, Maya. 2009. "What Do People Want to Feel and Why?: Pleasure and Utility in Emotion Regulation." Current Directions in Psychological Science 18(2):101-5. doi: 10.1111/j.1467-8721.2009.01617.x.

Todd, Rebecca M., William A. Cunningham, Adam K. Anderson, and Evan Thompson. 2012. "Affect-Biased Attention as Emotion Regulation." Trends in Cognitive Sciences 16(7):365-72. doi: 10.1016/j.tics.2012.06.003.

Tracy, J. L., and D. Matsumoto. 2008. "The Spontaneous Expression of Pride and Shame: Evidence for Biologically Innate Nonverbal Displays." Proceedings of the National Academy of Sciences 105(33):11655-60. doi: 10.1073/pnas.0802686105.

Tracy, Jessica L., and Richard W. Robins. 2008. "The Nonverbal Expression of Pride: Evidence for Cross-Cultural Recognition." Journal of Personality and Social Psychology 94(3):516-30. doi: 10.1037/0022-3514.94.3.516.

Tracy, Jessica L., Richard W. Robins, and Kristin H. Lagattuta. 2005. "Can Children Recognize Pride?" Emotion (Washington, D.C.) 5(3):251-57. doi: 10.1037/15283542.5.3.251.

Van Kleef, Gerben A. 2009. "How Emotions Regulate Social Life: The Emotions as Social Information (EASI) Model." Current Directions in Psychological Science 18(3):184-88. doi: 10.1111/j.1467-8721.2009.01633.x.

Vansteenkiste, Maarten, Tinneke Timmermans, Willy Lens, Bart Soenens, and Anja Van den Broeck. 2008. "Does Extrinsic Goal Framing Enhance Extrinsic GoalOriented Individuals' Learning and Performance? An Experimental Test of the Match Perspective versus Self-Determination Theory." Journal of Educational Psychology 100(2):387-97. doi: 10.1037/0022-0663.100.2.387.

Vanutelli, Maria Elide, Laura Gatti, Laura Angioletti, and Michela Balconi. 2017. "Affective Synchrony and Autonomic Coupling during Cooperation: A Hyperscanning Study." BioMed Research International 2017:e3104564. Retrieved November 10, 2020 (https://www.hindawi.com/journals/bmri/2017/3104564/). 


\section{Social and Affective Dynamics and their Survival Benefits}

Wood, Adrienne, Magdalena Rychlowska, Sebastian Korb, and Paula Niedenthal. 2016. "Fashioning the Face: Sensorimotor Simulation Contributes to Facial Expression Recognition." Trends in Cognitive Sciences 20(3):227-40. doi: 10.1016/j.tics.2015.12.010.

Woodyatt, Lydia, and Michael Wenzel. 2013. "The Psychological Immune Response in the Face of Transgressions: Pseudo Self-Forgiveness and Threat to Belonging." Journal of Experimental Social Psychology 49(6):951-58. doi: 10.1016/j.jesp.2013.05.016.

Adler, A. (1930). Social interest: A challenge to mankind (J. L. R. Vaughan, Trans.). New York: Putnam.

Alexander, R. (1971). The search for an evolutionary philosophy of man. Proceedings of the Royal Society Victoria, 84, 99-120.

Alexander, R. (1974). The evolution of social behavior. Annual Review of Ecology and Systematics, 5, 325-383.

Anderson, C., Hildreth, J. A., \& Howland, L. (2015). Is the desire for status a fundamental human motive? A review of the empirical literature. Psychol Bull, 141(3), 574-601. doi:10.1037/a0038781

Anderson, C., \& Kilduff, G. J. (2009). Why do dominant personalities attain influence in face-to-face groups? The competence-signaling effects of trait dominance. J Pers Soc Psychol, 96(2), 491-503. doi:10.1037/a0014201

Anderson, N. H. (1968). Likableness ratings of 555 personality-trait words. J Pers Soc Psychol, 9(3), 272-279.

Anstey, M. L., Rogers, S. M., Ott, S. R., Burrows, M., \& Simpson, S. J. (2009). Serotonin mediates behavioral gregarization underlying swarm formation in desert locusts. Science, 323(5914), 627-630. doi:10.1126/science.1165939

Apicella, C. L., Marlowe, F. W., Fowler, J. H., \& Christakis, N. A. (2012). Social networks and cooperation in hunter-gatherers. Nature, 481(7382), 497-501.

doi:10.1038/nature10736

Arnold, K., Owens, I., \& Goldizen, A. (2005). Division of labour within cooperatively breeding groups. Behaviour, 142, 1577-1590.

Aron, A., Fisher, H., Mashek, D. J., Strong, G., Li, H., \& Brown, L. L. (2005). Reward, motivation, and emotion systems associated with early-stage intense romantic love. $J$ Neurophysiol, 94(1), 327-337. doi:10.1152/jn.00838.2004 Bandura, A. (1962). Social learning through imitation. In Lincoln (Ed.), Nebraska Symposium on Motivation: University of Nebraska Press.

Banerjee, R. (2002). Audience Effects on Self-Presentation in Childhood. Social Development, 11, 487-507. 


\section{Social and Affective Dynamics and their Survival Benefits}

Barth, J., Schneider, S., \& von Kanel, R. (2010). Lack of social support in the etiology and the prognosis of coronary heart disease: a systematic review and meta-analysis. Psychosom Med, 72(3), 229-238. doi:10.1097/PSY.0b013e3181d01611 Baumeister, R. F., \& Leary, M. R. (1995). The need to belong: desire for interpersonal attachments as a fundamental human motivation. Psychol Bull, 117(3), 497-529. Berger, J., Cohen, B., \& Zelditch, M. (1972). Status characteristics and social interaction. American Sociological Review, 37, 241-255.

Bhugra, D., Leff, J., Mallett, R., Morgan, C., \& Zhao, J. H. (2010). The culture and identity schedule a measure of cultural affiliation: acculturation, marginalization and schizophrenia. Int J Soc Psychiatry, 56(5), 540-556. doi:10.1177/0020764009358024 Bowlby, J. (1988). A secure base : clinical applications of attachment theory. London: Routledge.

Brewer, M. (1979). In-group bias in the minimal intergroup situation: A cognitivemotivational analysis. Psychological Bulletin, 86, 307-324.

Brewer, M. B. (2007). The importance of being we: human nature and intergroup relations. Am Psychol, 62(8), 726-738. doi:10.1037/0003-066X.62.8.728

Brown, B. (1968). The effects of need to maintain face on interpersonal bargaining. Journal of Experimental Social Psychology, 4, 107-122.

Bshary, R., \& Grutter, A. S. (2006). Image scoring and cooperation in a cleaner fish mutualism. Nature, 441(7096), 975-978. doi:10.1038/nature04755

Buttelmann, D., Zmyj, N., Daum, M., \& Carpenter, M. (2013). Selective imitation of ingroup over out-group members in 14-month-old infants. Child Dev, 84(2), 422-428. doi:10.1111/j.1467-8624.2012.01860.x

Byrne, R. W., \& Whiten, A. (1988). Machiavellian intelligence : social expertise and the evolution of intellect in monkeys, apes, and humans. Oxford

New York: Clarendon Press ;

Oxford University Press.

Campbell-Meiklejohn, D. K., Bach, D. R., Roepstorff, A., Dolan, R. J., \& Frith, C. D. (2010). How the opinion of others affects our valuation of objects. Curr Biol, 20(13), 1165-1170. doi:10.1016/j.cub.2010.04.055

Carlisle, D., \& Ellis, P. (1963). Prothoracid gland and gregarious behavior in locusts. Nature, 200, 603-604.

Carson, D. S., Garner, J. P., Hyde, S. A., Libove, R. A., Berquist, S. W., Hornbeak, K. B., ... Parker, K. J. (2015). Arginine Vasopressin Is a Blood-Based Biomarker of Social Functioning in Children with Autism. PLoS One, 10(7), e0132224.

doi:10.1371/journal.pone.0132224

Castiello, U., Becchio, C., Zoia, S., Nelini, C., Sartori, L., Blason, L., . . Gallese, V. (2010). Wired to be social: the ontogeny of human interaction. PLoS One, 5(10), e13199. doi:10.1371/journal.pone.0013199 


\section{Social and Affective Dynamics and their Survival Benefits}

Clutton-Brock, T. (2002). Breeding together: kin selection and mutualism in cooperative vertebrates. Science, 296(5565), 69-72. doi:10.1126/science.296.5565.69

Cohen, S., Doyle, W. J., Skoner, D. P., Rabin, B. S., \& Gwaltney, J. M., Jr. (1997). Social ties and susceptibility to the common cold. JAMA, 277(24), 1940-1944.

Collins, J., Baer, B., \& Weber, E. (2015). Sexual selection, conspicuous consumption and economic growth. Journal of Bioeconomics, 17, 189-206.

Crockett, M. J. (2013). Models of morality. Trends Cogn Sci, 17(8), 363-366.

doi:10.1016/j.tics.2013.06.005

De Fraja, G. (2009). The Origin of Utility : Sexual Selection and Conspicuous

Consumption. Journal of Economic Behavior \& Organization, 72, 51-69.

de Waal, F. (2011). What is an animal emotion? Annals of the New York Academy of

Sciences, 1224, 191-206.

Deaner, R. O., Khera, A. V., \& Platt, M. L. (2005). Monkeys pay per view: adaptive valuation of social images by rhesus macaques. Curr Biol, 15(6), 543-548.

doi:10.1016/j.cub.2005.01.044

Deci, E., \& Ryan, R. (2008). Self-Determination theory: A macrotheory of human

motivation, development, and health. Canadian Psychology, 49, 182-185.

Delgado, M. R., Frank, R. H., \& Phelps, E. A. (2005). Perceptions of moral character modulate the neural systems of reward during the trust game. Nat Neurosci, 8(11), 1611-1618. doi:10.1038/nn1575

Delgado, M. R., Schotter, A., Ozbay, E. Y., \& Phelps, E. A. (2008). Understanding overbidding: using the neural circuitry of reward to design economic auctions. Science, 321(5897), 1849-1852. doi:10.1126/science.1158860

Deutsch, M. (1949). A Theory of Co-operation and Competition. Human Relations, 2, 129-152.

Diamond, J. (1978). Niche shifts and the rediscovery of interspecific competition. American Scientist, 66, 322-331.

Diamond, J. (1997). Guns, Germs and Steel: The fates of human societies. New York: W.W. Norton \& Company.

Diehl, M. (1990). The Minimal Group Paradigm: Theoretical Explanations and Empirical Findings. European Review of Social Psychology, 1, 263-292.

Dolinsky, A. L., \& Stinerock, R. (1998). Cultural affiliation and the importance of health care attributes. Marketers can develop segmentation strategies for targeted patient groups. Mark Health Serv, 18(1), 28-37.

Dunbar, R. (1993). Coevolution of neocortical size, group size and language in humans. Behavioral and Brain Sciences, 16, 681-735.

Dunbar, R. I. M. (2010). How many friends does one person need? : Dunbar's number and other evolutionary quirks. Cambridge, Mass.: Harvard University Press. 


\section{Social and Affective Dynamics and their Survival Benefits}

Eisenberger, N. I., \& Cole, S. W. (2012). Social neuroscience and health: neurophysiological mechanisms linking social ties with physical health. Nat Neurosci, 15(5), 669-674. doi:10.1038/nn.3086

Ellemers, N., Spears, R., \& Doosje, B. (1997). Sticking Together or Falling Apart: InGroup Identification as a Psychological Determinant of Group Commitment Versus Individual Mobility. Journal of Personality and Social Psychology, 72, 617-626. Ellis, L. (1993). Social stratification and socioeconomic inequality. Westport Conn.: Praeger.

Engelmann, D., \& Fischbacher, U. (2009). Indirect reciprocity and strategic reputation building in an experimental helping game. Games and Economic Behavior, 67, 399407.

Engelmann, J. M., Herrmann, E., \& Tomasello, M. (2012). Five-year olds, but not chimpanzees, attempt to manage their reputations. PLoS One, 7(10), e48433. doi:10.1371/journal.pone.0048433 Fehr, E., Bernhard, H., \& Rockenbach, B. (2008). Egalitarianism in young children. Nature, 454(7208), 1079-1083. doi:10.1038/nature07155

Fehr, E., \& Fischbacher, U. (2003). The nature of human altruism. Nature, 425(6960), 785-791. doi:10.1038/nature02043

Fehr, E., \& Gachter, S. (2002). Altruistic punishment in humans. Nature, 415(6868), 137140. doi:10.1038/415137a

Feldman Hall, O., \& Mobbs, D. (2015). A neural network for moral decision making. In A. W. Toga (Ed.), Brain mapping: An encyclopedic reference (pp. 205-210): Academic Press.

Fiske, S. (2002). Five core social motives, plus or minus five. In S. F. S.J. Spencer, M.P. Zanna \& J. Olsen (Ed.), Motivated social perception: The Ontario Symposium (pp. 233246). Mahwah, N.J.: Erlbaum.

Flinn, M., Geary, D., \& Ward, C. (2005). Ecological dominance, social competition, and coalitionary arms races: Why humans evolved extraordinary intelligence. Evolution and Human Behavior, 26, 10-46.

Foster, W., \& Treherne, J. (1981). Evidence for the dilution effect in the selfish herd from fish predation on a marine insect. Nature, 293, 466-467.

Frank, R. H. (1999). Luxury Fever: Why Money Fails to Satisfy in an Era of Excess. New York: The Free Press.

Galton, F. (1907). The wisdom of crowds. Nature, 75, 450-451.

Garfield, A., Cowley, M., Smith, F., Moorwood, K., Stewart-Cox, J., Gilroy, K., . . . Ward, A. (2011). Distinct physiological and behavioural functions for parental alleles of imprinted Grb10. Nature, 469, 534-538. 


\section{Social and Affective Dynamics and their Survival Benefits}

Gilbert, D. T., Killingsworth, M. A., Eyre, R. N., \& Wilson, T. D. (2009). The surprising power of neighborly advice. Science, 323(5921), 1617-1619.

doi:10.1126/science.1166632

Giraldeau, L. (1984). Group foraging: The skill pool effect and frequency-dependent learning. The American Naturalist, 124, 72-79.

Gurven, M. (2004). Reciprocal altruism and food sharing decisions among Hiwi and Ache hunter-gatherers. Behavioral Ecology and Sociobiology, 56, 366-380.

Guth, W., Schmittberger, R., \& Schwarze, B. (1982). An experimental analysis of

ultimatum bargaining. Journal of Economic Behavior \& Organization, 3, 367-388.

Haldane, J. B. S. (1932). The causes of evolution. London, New York etc.: Longmans, Green and co.

Haley, K., \& Fessler, D. (2005). Nobody's watching? Subtle cues affect generosity in an anonymous economic game. Evolution and Human Behavior, 26, 245-256.

Hamilton, W. D. (1964a). The genetical evolution of social behaviour. I. J Theor Biol, 7(1), 1-16.

Hamilton, W. D. (1964b). The genetical evolution of social behaviour. II. J Theor Biol, 7(1), 17-52.

Harlow, H. F. (1958). The nature of love. American Psychologist, 13, 673-685.

Hatfield, E., \& Rapson, R. (1993). Love and attachment processes. In M. L. J. Haviland (Ed.), Handbook of Emotions. New York: Guilford Press.

Henke, J. M., \& Bassler, B. L. (2004). Bacterial social engagements. Trends Cell Biol, 14(11), 648-656. doi:10.1016/j.tcb.2004.09.012

Hepach, R., Vaish, A., \& Tomasello, M. (2012). Young children are intrinsically motivated to see others helped. Psychol Sci, 23(9), 967-972.

doi:10.1177/0956797612440571

Higgins, T. (1987). Self-discrepancy: A theory relating self and affect. Psychological Review, 94, 319-340.

Higgins, T. (1992). Achieving 'Shared Reality' in the Communication Game: A Social Action That Creates Meaning. Journal of Language and Social Psychology, 11, 107131.

Hogg, M. A., \& Abrams, D. (1988). Social identifications : a social psychology of intergroup relations and group processes. London; New York: Routledge.

Huberman, B., Loch, C., \& Onculer, A. (2004). Status as a valued resource. Social Psychology Quarterly, 67, 103-114.

Humphrey, N. (1976). The social function of intellect. In P. P. G. B. a. R.A. Hinde (Ed.), Growing Points in Ethology (pp. 303-317). Cambridge: Cambridge University Press. Izuma, K., Saito, D. N., \& Sadato, N. (2010). Processing of the incentive for social approval in the ventral striatum during charitable donation. J Cogn Neurosci, 22(4), 621-631. doi:10.1162/jocn.2009.21228 


\section{Social and Affective Dynamics and their Survival Benefits}

Jonas, E., Schulz-Hardt, S., \& Frey, D. (2005). Giving advice or making decisions in someone else's place: the influence of impression, defense, and accuracy motivation on the search for new information. Pers Soc Psychol Bull, 31(7), 977-990.

doi:10.1177/0146167204274095

Jordan, J. J., Hoffman, M., Bloom, P., \& Rand, D. G. (2016). Third-party punishment as a costly signal of trustworthiness. Nature, 530(7591), 473-476.

doi:10.1038/nature16981

Jordan, J. J., Hoffman, M., Nowak, M. A., \& Rand, D. G. (2016). Uncalculating cooperation is used to signal trustworthiness. Proc Natl Acad Sci U S A, 113(31), 86588663. doi:10.1073/pnas.1601280113

Kappes, A., Kahane, G., \& Crockett, M. J. (2016). From risk to fairness. Proc Natl Acad Sci U S A, 113(42), 11651-11653. doi:10.1073/pnas.1614111113

Kendrick, K. M. (2004). The neurobiology of social bonds. J Neuroendocrinol, 16(12), 1007-1008. doi:10.1111.1365-2826.2004.01262.x

Klein, O., Spears, R., \& Reicher, S. (2007). Social identity performance: extending the strategic side of SIDE. Pers Soc Psychol Rev, 11(1), 28-45.

doi:10.1177/1088868306294588

Kosfeld, M., Heinrichs, M., Zak, P. J., Fischbacher, U., \& Fehr, E. (2005). Oxytocin

increases trust in humans. Nature, 435(7042), 673-676. doi:10.1038/nature03701

Krebs, J. (1972). Flocking and feeding in the great tit Parus major: an experimental study. Ibis, 114, 507-530.

Krebs, J., \& Davies, N. (1997). Behavioral ecology: An evolutionary approach. Oxford: Wiley-Blackwell.

Kross, E., Berman, M. G., Mischel, W., Smith, E. E., \& Wager, T. D. (2011). Social rejection shares somatosensory representations with physical pain. Proc Natl Acad Sci U S A, 108(15), 6270-6275. doi:10.1073/pnas.1102693108

Lambert, N. M., Stillman, T. F., Hicks, J. A., Kamble, S., Baumeister, R. F., \& Fincham, F. D. (2013). To belong is to matter: sense of belonging enhances meaning in life. Pers Soc Psychol Bull, 39(11), 1418-1427. doi:10.1177/0146167213499186

Leary, M. R., Jongman-Sereno, K., \& Diebels, K. (2014). The pursuit of status: A selfpresentational perspective on the quest for social value. In J. L. T. J. T. Cheng, \& C. Anderson (Ed.), The psychology of

social status (pp. 159-178). New York: Springer.

Leary, M. R., \& Kowalski, R. (1990). Impression Management: A Literature Review and Two-Component Model. Psychological Bulletin, 107, 34-47.

Livnat, A., Papadimitriou, C., Dushoff, J., \& Feldman, M. W. (2008). A mixability theory for the role of sex in evolution. Proc Natl Acad Sci U S A, 105(50), 19803-19808.

doi:10.1073/pnas.0803596105 


\section{Social and Affective Dynamics and their Survival Benefits}

Loucks, E. B., Sullivan, L. M., D'Agostino, R. B., Sr., Larson, M. G., Berkman, L. F., \& Benjamin, E. J. (2006). Social networks and inflammatory markers in the Framingham Heart Study. J Biosoc Sci, 38(6), 835-842. doi:10.1017/S0021932005001203 Maslow, A. (1943). A theory of human motivation. Psychological Review, 50, 370-396. Mason, R. (1984). Conspicuous Consumption: A Literature Review. European Journal of Marketing, 18, 26-39.

McClelland, D. C. (1965). Toward a Theory of Motive Acquisition. Am Psychol, 20, 321333.

McClelland, D. C., \& Burnham, D. H. (2003). Power is the great motivator. 1976. Harv Bus Rev, 81(1), 117-126.

McNamara, J. M., Stephens, P. A., Dall, S. R., \& Houston, A. I. (2009). Evolution of trust and trustworthiness: social awareness favours personality differences. Proc Biol Sci, 276(1657), 605-613. doi:10.1098/rspb.2008.1182

Memushi, A. (2014). Conspicuous consumption and Albanians: Determinant factors. South-Eastern Europe Journal of Economics, 1, 65-87.

Milgram, S. (1964). Group Pressure and Action against a Person. J Abnorm Psychol, 69, 137-143.

Mobbs, D., Hagan, C. C., Yu, R., Takahashi, H., FeldmanHall, O., Calder, A. J., \& Dalgleish, T. (2015). Reflected glory and failure: the role of the medial prefrontal cortex and ventral striatum in self vs other relevance during advice-giving outcomes. Soc Cogn Affect Neurosci, 10(10), 1323-1328. doi:10.1093/scan/nsv020

Moles, A., Kieffer, B. L., \& D'Amato, F. R. (2004). Deficit in attachment behavior in mice lacking the mu-opioid receptor gene. Science, 304(5679), 1983-1986.

doi:10.1126/science.1095943

Moll, H., \& Tomasello, M. (2007). Cooperation and human cognition: the Vygotskian intelligence hypothesis. Philos Trans R Soc Lond B Biol Sci, 362(1480), 639-648. doi:10.1098/rstb.2006.2000

Nonacs, P., \& Kapheim, K. M. (2007). Social heterosis and the maintenance of genetic diversity. J Evol Biol, 20(6), 2253-2265. doi:10.1111/j.1420-9101.2007.01418.x Nowak, M. A. (2006). Five rules for the evolution of cooperation. Science, 314(5805), 1560-1563. doi:10.1126/science.1133755

Onishi, K. H., \& Baillargeon, R. (2005). Do 15-month-old infants understand false beliefs? Science, 308(5719), 255-258. doi:10.1126/science.1107621

Park, R., \& Burgess, E. (1921). Introduction to the science of sociology. Chicago: University of Chicago Press.

Pedersen, C. A., Vadlamudi, S. V., Boccia, M. L., \& Amico, J. A. (2006). Maternal behavior deficits in nulliparous oxytocin knockout mice. Genes Brain Behav, 5(3), 274281. doi:10.1111/j.1601-183X.2005.00162.x 


\section{Social and Affective Dynamics and their Survival Benefits}

Piazza, J., Bering, J. M., \& Ingram, G. (2011). "Princess Alice is watching you": children's belief in an invisible person inhibits cheating. J Exp Child Psychol, 109(3), 311-320. doi:10.1016/j.jecp.2011.02.003

Pruetz, J. D., \& Lindshield, S. (2012). Plant-food and tool transfer among savanna chimpanzees at Fongoli, Senegal. Primates, 53(2), 133-145. doi:10.1007/s10329-0110287-x

Rofe, Y. (1984). Stress and affiliation: A utility theory. Psychological Review, 91, 235250.

Rosen, S., \& Tesser, A. . (1970). On reluctance to communicate undesirable information: The MUM effect. Sociometry, 33, $253-263$.

Ross, H. E., \& Young, L. J. (2009). Oxytocin and the neural mechanisms regulating social cognition and affiliative behavior. Front Neuroendocrinol, 30(4), 534-547. doi:10.1016/j.yfrne.2009.05.004

Rotter, J. (1954). Social learning and clinical psychology. Englewood Cliffs, NJ: Prentice-Hall.

Sarnoff, I., \& Zimbardo, P. G. (1961). Anxiety, fear, and social affiliation. J Abnorm Soc Psychol, 62, 356-363.

Schachter, S. (1959). The psychology of affiliation. CA: Stanford University Press.

Schmidt, M. F., \& Sommerville, J. A. (2011). Fairness expectations and altruistic sharing in 15-month-old human infants. PLoS One, 6(10), e23223.

doi:10.1371/journal.pone.0023223

Seeman, T. E., \& McEwen, B. S. (1996). Impact of social environment characteristics on neuroendocrine regulation. Psychosom Med, 58(5), 459-471.

Selman, R. L. (1980). The growth of interpersonal understanding: developmental and clinical analyses. New York: Academic Press.

Selman, R. L., \& Schultz, L. H. (1990). Making a friend in youth : developmental theory and pair therapy. Chicago: University of Chicago Press.

Seyfarth, R. M., \& Cheney, D. L. (2012). The evolutionary origins of friendship. Annu Rev Psychol, 63, 153-177. doi:10.1146/annurev-psych-120710-100337

Shultz, S., Opie, C., \& Atkinson, Q. D. (2011). Stepwise evolution of stable sociality in primates. Nature, 479(7372), 219-222. doi:10.1038/nature10601

Silk, J. B. (2007). The adaptive value of sociality in mammalian groups. Philos Trans $R$ Soc Lond B Biol Sci, 362(1480), 539-559. doi:10.1098/rstb.2006.1994

Singer, T., Seymour, B., O'Doherty, J. P., Stephan, K. E., Dolan, R. J., \& Frith, C. D. (2006). Empathic neural responses are modulated by the perceived fairness of others. Nature, 439(7075), 466-469. doi:10.1038/nature04271

Spears, R. (1995). Isolating the Collective Self The Self in European and North American Culture: Development and Processes (pp. 309-322). Netherlands: Springer Netherlands. 


\section{Social and Affective Dynamics and their Survival Benefits}

Spears, R. (2011). Group identities: The social identity perspective Handbook of Identity Theory and Research (pp. 201-224). New York: Springer New York. Steptoe, A., Shankar, A., Demakakos, P., \& Wardle, J. (2013). Social isolation, loneliness, and all-cause mortality in older men and women. Proc Natl Acad Sci U S A, 110(15), 5797-5801. doi:10.1073/pnas. 1219686110

Stets, J., \& Burke, P. (2000). Identity theory and social identity theory. Social Psychology Quarterly, 63, 224-237.

Surowiecki, J. (2004). The wisdom of crowds. New York: W.W. Norton \& Company, Inc. Svetlova, M., Nichols, S. R., \& Brownell, C. A. (2010). Toddlers' prosocial behavior: from instrumental to empathic to altruistic helping. Child Dev, 81(6), 1814-1827.

doi:10.1111/j.1467-8624.2010.01512.x

Tajfel, H., \& Turner, J. (1986). The social identity theory of intergroup behaviour. In S. W. W. G. Austin (Ed.), Psychology of intergroup relations. Chicago: Nelson-Hall. Talhelm, T., Zhang, X., Oishi, S., Shimin, C., Duan, D., Lan, X., \& Kitayama, S. (2014). Large-scale psychological differences within China explained by rice versus wheat agriculture. Science, 344(6184), 603-608. doi:10.1126/science.1246850

Taylor, S. E., Klein, L. C., Lewis, B. P., Gruenewald, T. L., Gurung, R. A., \& Updegraff, J. A. (2000). Biobehavioral responses to stress in females: tend-and-befriend, not fight-orflight. Psychol Rev, 107(3), 411-429.

Telzer, E. H., Flannery, J., Shapiro, M., Humphreys, K. L., Goff, B., Gabard-Durman, L., . .. Tottenham, N. (2013). Early experience shapes amygdala sensitivity to race: an international adoption design. J Neurosci, 33(33), 13484-13488.

doi:10.1523/JNEUROSCI.1272-13.2013

Tennie, C., Frith, U., \& Frith, C. D. (2010). Reputation management in the age of the world-wide web. Trends Cogn Sci, 14(11), 482-488. doi:10.1016/j.tics.2010.07.003 Terborgh, J., \& Janson, C. (1986). The socioecology of primate groups. Annual Review of Ecology and Systematics, 17, 111-136.

Tolman, E. (1932). Purposive behavior in animals and men. New York: The Century Co. Tomasello, M., Carpenter, M., Call, J., Behne, T., \& Moll, H. (2005). Understanding and sharing intentions: the origins of cultural cognition. Behav Brain Sci, 28(5), 675-691; discussion 691-735. doi:10.1017/S0140525X05000129

Tomasello, M., Melis, A., Tennie, C., Wyman, E., \& Herrmann, E. (2012). Two Key Steps in the Evolution of Human Cooperation: The Interdependence Hypothesis. Current Anthropology, 53, 673-692.

Torres, V. O., Montagna, T. S., Raizer, J., \& Antonialli-Junior, W. F. (2012). Division of labor in colonies of the eusocial wasp, Mischocyttarus consimilis. J Insect Sci, 12, 21. doi:10.1673/031.012.2101

Turner, J., Brown, R., \& Tajfel, H. (1979). Social comparison and group interest in ingroup favoritism. European Journal of Social Psychology, 9(187-204). 


\section{Social and Affective Dynamics and their Survival Benefits}

Turner, M., Pratkanis, A., Probasco, P., \& Leve, C. (1992). Threat, cohesion, and group effectiveness: Testing a social identity maintenance perspective on groupthink. Journal of Personality and Social Psychology, 63, 781-796.

Valenza, E., Simion, F., Cassia, V. M., \& Umilta, C. (1996). Face preference at birth. J Exp Psychol Hum Percept Perform, 22(4), 892-903.

Van Bavel, J., Feldman Hall, O., \& Mende-Siedlecki, P. (2015). The neuroscience of moral cognition: from dual process to dynamic systems. Current Opinion in Psychology, 6, 167-172.

van den Bos, W., Li, J., Lau, T., Maskin, E., Cohen, J., \& McClure, S. (2008). The value of victory, social origins of the winner's curse in common value auctions. Judgment and Decision Making, 3, 483-492.

van Leengoed, E., Kerker, E., \& Swanson, H. (1987). Inhibition of post-partum maternal behaviour in the rat by injecting an oxytocin antagonist into the cerebral ventricles. Journal of Endocrinology, 112, 275-282.

Vansteenkiste, M., Simons, J., Lens, W., Sheldon, K. M., \& Deci, E. L. (2004). Motivating learning, performance, and persistence: the synergistic effects of intrinsic goal contents and autonomy-supportive contexts. J Pers Soc Psychol, 87(2), 246-260.

doi:10.1037/0022-3514.87.2.246

Veblen, T. (1899). The theory of the leisure class; an economic study in the evolution of institutions. New York, London,: The Macmillan company;

Macmillan \& co., Itd.

Verkuyten, M., \& Masson, K. (1996). Culture and gender differences in the perception of friendship by adolescents. International Journal of Psychology, 31, 207-217.

Warneken, F., \& Tomasello, M. (2009). The roots of human altruism. Br J Psychol, 100(Pt 3), 455-471. doi:10.1348/000712608X379061

Wegner, D. M., Erber, R., \& Raymond, P. (1991). Transactive memory in close relationships. J Pers Soc Psychol, 61(6), 923-929.

West, P. (2004). Conspicuous compassion : why sometimes it really is cruel to be kind London: Civitas.

West, S. A., Griffin, A. S., \& Gardner, A. (2007). Social semantics: altruism, cooperation, mutualism, strong reciprocity and group selection. J Evol Biol, 20(2), 415-432.

doi:10.1111/j.1420-9101.2006.01258.x

Wilson, D. S., \& Wilson, E. O. (2007). Rethinking the theoretical foundation of sociobiology. Q Rev Biol, 82(4), 327-348.

Wilson, E. (2012). The social conquest of earth. New York: W.W. Norton \& Co. Yu, R., Calder, A. J., \& Mobbs, D. (2014). Overlapping and distinct representations of advantageous and disadvantageous inequality. Hum Brain Mapp, 35(7), 3290-3301. 


\section{Social and Affective Dynamics and their Survival Benefits}

Zehavi, A., \& Zahavi, A. (1997). The handicap principle : a missing piece of Darwin's puzzle. New York: Oxford University Press.

Zimmer-Gembeck, M. J. (2002). The development of romantic relationships and adaptations in the system of peer relationships. J Adolesc Health, 31(6 Suppl), 216225. 